\title{
Asset Encumbrance, Bank Funding and Financial Fragility
}

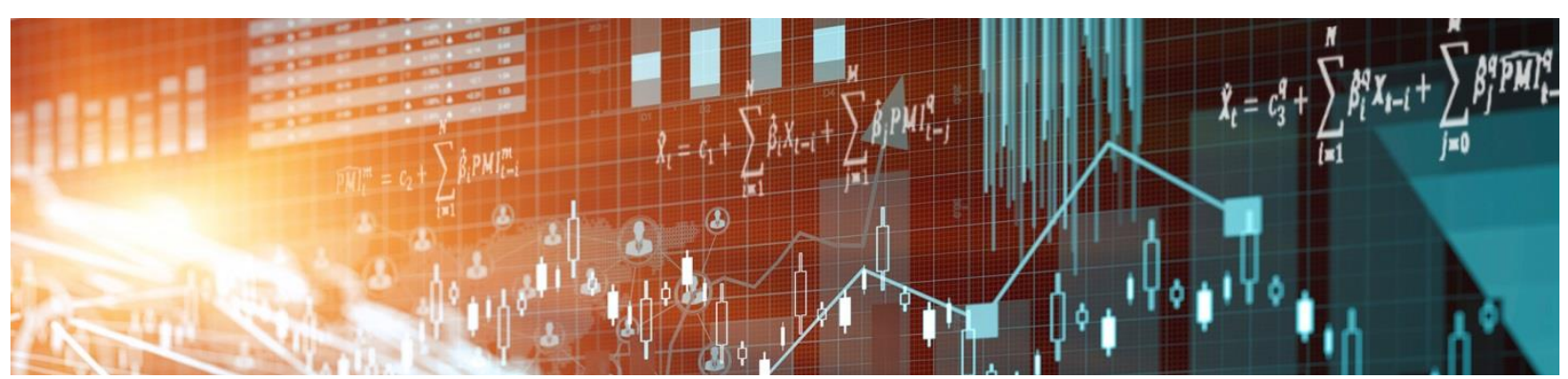

by Toni Ahnert, Kartik Anand, Prasanna Gai and James Chapman 
Bank of Canada Staff Working Paper 2016-16

April 2016

\title{
Asset Encumbrance, Bank Funding and Financial Fragility
}

by

Toni Ahnert, ${ }^{1}$ Kartik Anand, ${ }^{2}$ Prasanna Gai ${ }^{3}$ and James Chapman ${ }^{1}$

\author{
${ }^{1}$ Financial Stability Department \\ Bank of Canada \\ Ottawa, Ontario, Canada K1A OG9 \\ tahnert@bankofcanada.ca \\ jchapman@bankofcanada.ca \\ 2Deutsche Bundesbank \\ 60431 Frankfurt am Main, Germany \\ kartik.anand@bundesbank.de \\ 3University of Auckland \\ Auckland 1142, New Zealand \\ p.gai@auckland.ac.nz
}




\section{Acknowledgements}

We are indebted to Jean-Charles Rochet for extensive feedback. We thank Jason Allen, Xavier Freixas, Douglas Gale, Agnese Leonello, Frank Milne, and seminar participants at the Alberta School of Business, University of Amsterdam, Bank of Canada, Carleton University, Danmarks Nationalbank, European Central Bank, Frankfurt School, Humboldt (Berlin), the Monetary Authority of Singapore, HEC Montréal, McGill University, Queen's University, the Reserve Bank of New Zealand, Victoria University (Wellington) and the FDIC Bank Research Conference 2015, the NFA 2015 Conference, and the RIDGE 2015 Workshop on Financial Stability for comments. First version: November 2012. Prasanna Gai thanks the Warden and Fellows of All Souls College, Oxford for their gracious hospitality during the preparation of this paper; he also acknowledges financial support from the University of Auckland Faculty Research Development Fund (\#3000875). 


\begin{abstract}
How does asset encumbrance affect the fragility of intermediaries subject to rollover risk? We offer a model in which a bank issues covered bonds backed by a pool of assets that is bankruptcy remote and replenished following losses. Encumbering assets allows a bank to raise cheap secured debt and expand profitable investment, but it also concentrates risk on unsecured debt and thus exacerbates fragility and raises unsecured funding costs. Deposit insurance or wholesale funding guarantees induce excessive encumbrance and fragility. To mitigate such risk shifting, we study prudential regulatory tools, including limits on encumbrance, minimum capital requirements and surcharges for encumbrance.
\end{abstract}

JEL classification: D82, G01, G21, G28

Bank classification: Financial institutions; Financial stability; Financial system

regulation and policies

\title{
Résumé
}

De quelle manière les actifs grevés accentuent-ils la fragilité des intermédiaires exposés au risque de refinancement? Pour répondre à cette question, nous proposons un modèle dans lequel une banque émet des obligations sécurisées adossées à des actifs qui sont à l'abri de la faillite et remplacés en cas de perte de valeur. En grevant des actifs, un établissement bancaire se donne la possibilité d'emprunter à bon marché par une émission de titres de créance garantis et d'investir davantage dans des placements rentables; ce faisant, il concentre le risque sur la dette non garantie et, dès lors, accroît nettement sa propre fragilité tout en faisant monter le coût du financement non garanti. Les garanties assorties à l'assurance-dépôt ou au financement de gros entraînent une forte hausse des charges grevant les actifs et une fragilité excessive. Nous examinons le rôle que peuvent jouer certains instruments prudentiels pour limiter le transfert du risque : plafonnement du niveau des actifs grevés, exigences minimales de fonds propres et imposition de frais supplémentaires si des actifs sont grevés.

Classification JEL : D82, G01, G21, G28

Classification de la Banque : Institutions financières; Stabilité financière;

Réglementation et politiques relatives au système financier 


\section{Non-Technical Summary}

Covered bonds have formed a cornerstone of bank funding in Europe since the late eighteenth century, and have been suggested to revitalize mortgage finance in the United States. Despite their longevity, a theoretical analysis is lacking. Moreover, policy-makers have become increasingly concerned about how the collateralization of bank balance sheets affects financial stability. In response, several jurisdictions, including Canada, have introduced measures to restrict covered bond issuance. This paper offers a positive analysis of how asset encumbrance affects bank fragility, and contributes to the regulatory debate.

Covered bonds are secured senior debt issued by banks. These are claims on originating banks, collateralized by a pool of mortgages that remain on the balance sheet. This pool is ring-fenced, or encumbered, and is thus bankruptcy-remote. Banks must replace nonperforming assets in this pool with performing assets of equivalent value and quality to maintain the requisite collateralization. These features provide strong incentives for banks to underwrite mortgages carefully, avoiding some of the pitfalls with the originate-to-distribute model. Indeed, investors perceive covered bonds as a safe asset without recorded default.

We derive normative implications about covered bond usage when some unsecured debt is guaranteed. Such schemes usually apply to retail deposits, but were also extended to unsecured wholesale debt during the global financial crisis. The privately optimal levels of covered bond usage and bank fragility are excessive, since the bank does not internalize the effect of encumbrance on the cost of providing the guarantee. Absent prudential safeguards, banks have incentives to issue covered bonds in order to shift risk to the guarantor, such as the CDIC. Accordingly, proposals that emphasize covered bonds as a means of reviving mortgage finance need to be accompanied by prudential regulation. We show that both a limit on the level of asset encumbrance and minimum capital requirements are effective tools. A surcharge for asset encumbrance paid to a deposit insurance fund - currently considered in Canada - has to be properly designed for it to be effective. 


\section{Introduction}

Following the global financial crisis, the moribund state of securitization markets in the United States has led some commentators to advocate secured funding by banks, notably in the form of covered bonds, as a means of reviving mortgage finance (Paulson, 2009; Soros, 2010). Campbell (2013, p.1) makes a forceful case that "the US has much to learn from mortgage finance in other countries, and specifically from the Danish implementation of the European covered bond system."

Covered bonds are secured senior debt issued by banks. These are claims on originating banks, collateralized by a pool of mortgages that remain on the balance sheet. This cover pool is ring-fenced, or encumbered, and therefore is bankruptcy remote. The cover pool is also dynamically replenished - non-performing assets are replaced with performing ones of equivalent value and quality to maintain the requisite collateralization. ${ }^{1}$ These institutional features incentivize banks to underwrite mortgages carefully, avoiding some of the pitfalls associated with the originate-to-distribute model (Bernanke, 2009; Keys et al., 2010; Purnanandam, 2011). Indeed, covered bonds are perceived as a safe asset by investors, since there are no recorded instances of default since their introduction in the eighteenth century. ${ }^{2}$

Despite their longevity as a financial instrument, there has been no theoretical analysis of covered bonds. Moreover, policy-makers have become increasingly concerned about the financial stability implications of the collateralization of bank balance sheets (CGFS, 2013). In response, several jurisdictions have introduced measures to restrict asset encumbrance. ${ }^{3}$ Our paper addresses these issues by offering a positive analysis of how asset encumbrance affects bank fragility and contributes to the normative debate on prudential regulation.

\footnotetext{
${ }^{1}$ Covered bond holders are also protected by dual recourse. If the value of the cover pool is insufficient to meet obligations, for the residual amount covered bond holders have a claim on unencumbered assets that is of equal seniority to unsecured claims. For institutional details on covered bonds, see Schwarcz (2011).

${ }^{2}$ Covered bonds have been a cornerstone of bank funding in Europe for over two centuries. They are especially important in Germany, where the Pfandbrief system was established by Frederick the Great in 1769 following the Seven Years War, and in Denmark following the Great Fire of Copenhagen in 1795. See Mastroeni (2001) and Wandschneider (2014) for historical details.

${ }^{3}$ These comprise limits on encumbrance (Australia, New Zealand), ceilings on the amount of secured funding by banks (Canada, US), and including encumbrance levels in deposit insurance premiums (Canada).
} 
In our model, a banker seeks funding to finance profitable investment opportunities. The banker has access to secured and unsecured debt markets, each with its own distinct investor clienteles. Debt is issued in two stages. First, building on Rochet and Vives (2004), the banker attracts unsecured debt from risk-neutral investors by offering demandable-debt. The banker invests these proceeds and its own funds. Second, the banker attracts secured debt from infinitely risk-averse investors, reflecting the highly restrictive mandates of pension funds and other large institutional investors. The banker issues covered bonds by encumbering, or ring-fencing, a fraction of existing assets into the cover pool that remains on its balance sheet. The cover pool is bankruptcy remote and the returns on its assets back the covered bond. The banker invests these additional funds raised from covered bond issuance.

The banker is subject to a balance sheet shock that has knock-on effects. First, since the cover pool is dynamically replenished, the banker replaces any non-performing assets in the cover pool with performing unencumbered assets. This maintains the value of the cover pool, but at the expense of the remainder of the balance sheet. Second, since premature liquidation is costly, the rollover decisions of unsecured creditors constitute a coordination problem that can lead to multiple equilibria (Diamond and Dybvig, 1983). To uniquely pin down behavior, we use a global games approach (Carlsson and van Damme, 1993; Morris and Shin, 2003; Goldstein and Pauzner, 2005). A private signal about the balance sheet shock informs the decision on whether to roll over unsecured debt. An unsecured debt run occurs if and only if the balance sheet shock is sufficiently high relative to the value of unencumbered assets. We link the incidence of ex-post runs to the banker's ex-ante issuance of covered bonds, and also solve for the unique face values of secured and unsecured debt. ${ }^{4}$

Our analysis suggests that covered bonds may not be the panacea that the proponents of such instruments might hope for. We highlight two opposing balance sheet effects of asset encumbrance and covered bond issuance. The first is a bank funding channel: greater covered bond issuance allows the banker to make additional profitable investments, which

\footnotetext{
${ }^{4}$ Our approach sidesteps Modigliani and Miller (1958). Costly liquidation of investment drives a wedge between debt and equity, and we assume that secured and unsecured debt markets are segmented.
} 
increases the expected equity value and reduces the potential for a run. The second is a riskconcentration channel: as more bonds are issued, the balance sheet shock is asymmetrically concentrated on unsecured creditors, exacerbating rollover risk and increasing the incidence of an unsecured debt run. The optimal level of asset encumbrance balances these two effects.

Covered bonds are safe assets for risk-averse investors and a stable and cheap source of bank funding. These results stem from two institutional features. The first feature is the replenishment of cover pool assets that protects covered bond holders from the balance sheet shock. The second feature is the bankruptcy-remoteness of the cover pool, whereby covered bond holders do not suffer a dilution of their claims in bankruptcy. ${ }^{5}$ At the same time, these features make unsecured debt more risky. Risk-neutral investors who hold unsecured debt suffer the full extent of the balance sheet shock, and can only lay claim to unencumbered assets in bankruptcy. As a result, bank fragility and the cost of unsecured debt are higher.

We study the normative implications of asset encumbrance when a proportion of unsecured debt is guaranteed. Such schemes usually apply to retail deposits, but were also extended to unsecured wholesale debt during the global financial crisis. ${ }^{6}$ Assuming a deeppocketed guarantor, a guarantee reduces both the rollover risk and the cost of unsecured funding, since the guarantor pays in bankruptcy. As a result, the privately optimal amount of encumbrance increases in the coverage of the guarantee. However, by encumbering assets, the banker shifts risks to the guarantor. Since the banker does not internalize the impact of encumbrance on the cost of the guarantee, the privately optimal levels of encumbrance and bank fragility are excessive. The extent of these excesses increases in guarantee coverage and in the dead-weight loss of raising the funds that back the guarantee (for instance, distortionary taxes).

\footnotetext{
${ }^{5}$ We also show that dual recourse is never called upon in equilibrium, since infinitely risk-averse investors evaluate holding a covered bond at the largest possible balance sheet shock. This result is consistent with the finding of Wandschneider (2014), who notes that dual recourse has never been called upon in practice.

${ }^{6}$ Between 2007 and 2011, many countries enacted special arrangements for banks to have new and existing wholesale bank funding guaranteed by the government until market conditions normalized. Recent analyses of the interplay between government guarantees and financial stability include König et al. (2014), Allen et al. (2015), and Leonello (2016).
} 
Our welfare criterion is constrained efficiency. A social planner chooses the amount of asset encumbrance that maximizes the expected payoffs net of the expected cost of the guarantee, taking the rollover risk of unsecured debt and the face values of guaranteed and non-guaranteed unsecured debt as given. We study three tools of prudential regulation, namely: (i) a limit on asset encumbrance; (ii) a minimum capital requirement; and (iii) a surcharge for asset encumbrance that is paid to a deposit insurance fund or as a contribution to a bailout fund. Several jurisdictions introduced regulations aimed at curbing excessive encumbrance - for example, limits on encumbrance in Australia and New Zealand, ceilings on the amount of secured funding in Canada and the United States, and an inclusion of encumbrance levels in deposit insurance premiums in Canada.

Our results suggest that imposing either a limit on encumbrance or a minimum capital requirement will induce the banker to choose the constrained efficient level of encumbrance, which induces the constrained efficient level of fragility. The unweighted capital ratio is given by the banker's own funds divided by total assets. A minimum capital ratio effectively limits the amount of secured-debt-funded investment, because more encumbrance lowers the capital ratio. Therefore, a floor on the capital ratio effectively becomes a bound on encumbrance. Finally, a surcharge for encumbrance reduces unencumbered assets and increases fragility, which induces the banker to reduce the level of encumbrance. However, if the surcharge schedule is continuous, the banker still pays a positive surcharge to encumber the constrained efficient level, which exacerbates fragility. Thus, constrained efficiency requires the surcharge schedule to have a large discontinuity at the constrained efficient level of encumbrance.

Our model offers several testable implications about asset encumbrance and the reliance on collateralized funding by banks. ${ }^{7}$ In line with the trade-off between profitability and fragility, higher liquidation values and cheaper unsecured debt reduce the rollover risk

\footnotetext{
${ }^{7}$ The existing literature on covered bonds is empirical. Carbo-Valverde et al. (2011) examine the extent to which covered bonds are a substitute for mortgage-backed securities. Prokopczuk and Vonhoff (2012) and Prokopczuk et al. (2013) study how market liquidity and asset quality affect the pricing of covered bonds. Beirne et al. (2011) empirically examine the effectiveness of the ECB's covered bond purchase program during 2009-10. Rixtel et al. (2015) contrast the issuance of various bonds by European banks.
} 
of unsecured funding, which lowers fragility and thus raises encumbrance levels. In contrast, greater conservatism in unsecured debt markets increases fragility and thus reduces encumbrance. A lower outside option of investors, perhaps because of lower competition or unconventional monetary policy, increases the bank funding channel and encumbrance. Higher risks to a bank's balance sheet increase fragility and therefore reduce encumbrance. Under mild conditions on parameters or distributional assumptions about the shock, encumbrance levels are higher for better-capitalized banks and for more-profitable investments.

Although we focus on covered bonds, our analysis is also relevant to other forms of secured funding. Central to our model is the interaction between the rollover risk of unsecured debt, the bankruptcy-remoteness of the cover pool, and the replenishment of assets backing secured debt. A similar interaction may be found for term repos, where safe harbor arrangements ensure the bankruptcy-remoteness of collateral (Goralnik, 2012), and the replenishment of asset pool occurs via the creditor's right to ask for a substitution of collateral or via variation margins. Credit card asset-backed securities also feature bankruptcy-remoteness and the replenishment of asset pools (Furletti, 2002).

An important contribution to the literature on bank funding is Greenbaum and Thakor (1987). They study the choice between deposit funding (on-balance-sheet) versus securitized funding (off-balance-sheet). Borrowers effectively choose the funding mode by signalling the private information about the quality of their projects. Higher-quality projects are securitized, while lower-quality projects remain on the bank's balance sheet and are funded with deposits. Prudential regulation, for example, the pricing of deposit insurance premiums and capital requirements, is shown to influence the relative appeal of deposit funding.

More recent work has begun to examine the interplay between secured and unsecured funding. Gai et al. (2013) and Eisenbach et al. (2014) adopt a balance sheet approach to examine the financial stability implications of alternative funding structures. Eisenbach et al. (2014) highlight some of the ex-post balance sheet dynamics associated with asset encumbrance and collateralized funding in the context of exogenous creditor behavior. Using 
global games techniques to describe endogenous creditor behavior, Gai et al. (2013) study how a bank's liquidity and solvency risks change with the composition of funding and show how "dashes for collateral" by short-term secured creditors can occur. In contrast, we explore the additional balance sheet dynamics of ex-post replenishment of the asset pool, endogenize the banker's ex-ante encumbrance choice, and determine the cost of secured and unsecured funding. Our paper also has points of contact with Matta and Perotti (2015), who study the role played by safe harbor provisions for repos in exacerbating funding liquidity risk.

The paper proceeds as follows. Section 2 sets out the model. Section 3 studies the rollover decision of unsecured creditors, and solves for the equilibrium in the secured and unsecured funding markets. Section 4 introduces guarantees for unsecured funding and studies the private incentives to shift risk to a guarantor, such as a deposit insurance fund. We examine how prudential safeguards can mitigate such risk shifting. Section 5 concludes.

\section{Model}

There are three dates, $t=0,1,2$, and three agents - a banker and two segmented clienteles of wholesale investors. The banker is risk-neutral and consumes at $t=2$. The first clientele of mass one is risk-neutral and indifferent between consuming at $t=1$ and $t=2$. By contrast, the second clientele of mass $\omega$ is infinitely risk-averse and consumes at $t=2$. This clientele may be thought of as pension funds or other large institutional investors, reflecting their mandates for high-quality and safe assets. All investors have a unit endowment at $t=0$ and access to safe storage that yields $r \geq 1$ at $t=2$.

At $t=0$, the banker has its own funds $E_{0}$ and seeks additional funding from investors to finance profitable and high-quality investments. Each investment matures at $t=2$ and its return is $R>r$. As in Diamond and Rajan (2001), the sale of investments yields a fraction $\psi \in(0,1)$ of the return at maturity, where $\psi R<r$. This cost reflects efficiency losses as asset ownership is transferred from skilled bankers to relatively unskilled investors. 
There are two rounds of funding at $t=0$. In the first, the unsecured funding round, risk-neutral investors place their endowment with the banker to receive a demandable debt claim as in Rochet and Vives (2004). Unsecured debt, $D_{0} \equiv 1$, can be withdrawn at $t=1$ or rolled over until $t=2$. This rollover decision is taken by a group of professional fund managers, indexed by $i \in[0,1]$. They face strategic complementarity in their decisions, whereby an individual manager's incentive to roll over increases in the proportion of managers who roll over. The relative cost to managers of rolling over, $0<\gamma<1$, plays an important role in this decision. ${ }^{8}$ The higher $\gamma$ is, the more conservative managers are, and the less likely that unsecured debt is rolled over. The face value of unsecured debt is independent of the withdrawal date, $D_{u} \leq R$. The banker invests the proceeds and its own funds.

In the second round, the secured funding round, the banker can attract covered bond funding from risk-averse investors by pledging high-quality assets. Specifically, the banker encumbers, or ring-fences, a fraction $0 \leq \alpha \leq 1$ of existing assets and places them in the cover pool - a bankruptcy remote vehicle on the bank's balance sheet. The level of asset encumbrance is publicly observed at $t=1$. We denote by $B_{0} \geq 0$ the total amount of covered bond funding raised, and by $D_{b} \leq R$ the face value of a covered bond at $t=2$. Table 1 shows the bank's balance sheet at $t=0$, once all wholesale funding is raised and the investment is made.

\begin{tabular}{lc|c}
\multicolumn{2}{c|}{ Assets } & Liabilities \\
\hline (cover pool) & $\alpha\left(1+E_{0}\right)$ & $B_{0}$ \\
(unencumbered assets) & $(1-\alpha)\left(1+E_{0}\right)+B_{0}$ & 1 \\
& & $E_{0}$
\end{tabular}

Table 1: Balance sheet at $t=0$

A defining feature of covered bonds is the dynamic replenishment of the cover pool after an adverse shock. Replenishment requires the banker to maintain the value of the cover pool at all dates, replacing non-performing assets in the cover pool with performing

\footnotetext{
${ }^{8}$ Rochet and Vives (2004) argue that the decisions of managers are governed by their compensation. In the case of a bankruptcy, a manager's relative compensation from rolling over is negative, $-c<0$. Otherwise, the relative compensation is positive, $b>0$. The conservativeness $\gamma \equiv \frac{c}{b+c}$ summarizes these parameters.
} 
unencumbered assets. Covered bond holders are thus protected and effectively become senior debt holders. But replenishment is detrimental to unsecured debt holders, since the entire shock is concentrated on them. We suppose that the balance sheet of the bank is subject to a shock $S \geq 0$ at $t=2$. The shock has a continuous probability density function $f(S)>0$ and a cumulative distribution function $F(S)$, where $f^{\prime}(S) \leq 0$, so that small shocks are more likely than larges ones. The banker observes the shock at $t=1$ and replenishes the cover pool. Table 2 shows the balance sheet at $t=2$ for a small shock, $S>0$, when all unsecured debt is rolled over at $t=1$. The value of bank equity at $t=2$ is denoted by $E(S)$.

\begin{tabular}{lc|c}
\multicolumn{2}{c|}{ Assets } & Liabilities \\
\hline (cover pool) & $R \alpha\left(1+E_{0}\right)$ & $B_{0} D_{b}$ \\
(unencumbered assets) & $R\left[(1-\alpha)\left(1+E_{0}\right)+B_{0}\right]-S$ & $D_{u}$ \\
& & $E(S)$
\end{tabular}

Table 2: Balance sheet at $t=2$ after a small shock

Another important feature of covered bonds is dual recourse. Under bankruptcy, the bank is closed and covered bond holders receive the market value of the cover pool, $\psi R \alpha\left(1+E_{0}\right)$, at $t=2$. If, however, this is insufficient to meet their claims, worth $D_{b} B_{0}$ in total, then each covered bond holder has a claim on the bank's unencumbered assets for the residual amount, $D_{b}-\psi R \alpha \frac{1+E_{0}}{B_{0}}$, at $t=2$, with equal seniority to unsecured debt holders.

If a proportion $\ell \in[0,1]$ of unsecured debt is not rolled over at $t=1$, the banker sells an amount $\frac{\ell D_{u}}{\psi R}$ in order to meet withdrawals. Owing to partial liquidation and the balance sheet shock, the value of unencumbered assets at the final date is $R\left[(1-\alpha)\left(1+E_{0}\right)+B_{0}-\frac{\ell D_{u}}{\psi R}\right]-S=$ $R\left[(1-\alpha)\left(1+E_{0}\right)+B_{0}\right]-\frac{\ell D_{u}}{\psi}-S$. Since the banker must service the remaining proportion $(1-\ell)$ of unsecured debt, with face value $D_{u}$, along with the residual claims of covered bond holders, as required by dual recourse, bankruptcy occurs at $t=2$ if

$$
R\left[(1-\alpha)\left(1+E_{0}\right)+B_{0}\right]-S-\frac{\ell D_{u}}{\psi}<(1-\ell) D_{u}+\left[D_{b} B_{0}-\alpha R \psi\left(1+E_{0}\right)\right] .
$$


If the shock were common knowledge, the rollover behavior of fund managers would be characterized by multiple equilibria, as illustrated in Figure 1. If no unsecured debt is rolled over, $\ell=1$, bankruptcy is avoided whenever the shock is smaller than a lower bound $\underline{S} \equiv$ $R\left[(1-\alpha)\left(1+E_{0}\right)+B_{0}\right]-\left(B_{0} D_{b}-\alpha R \psi\left(1+E_{0}\right)\right)-\frac{D_{u}}{\psi}$. For $S<\underline{S}$, it is a dominant strategy for fund managers to roll over. We assume that the banker is well-capitalized, $E_{0}>\frac{1-\psi^{2} R^{2}}{\psi^{2} R^{2}}$, so no run occurs absent a shock, $\underline{S}>0$. Likewise, if $\ell=0$, bankruptcy occurs whenever the shock is larger than an upper bound $\bar{S} \equiv R\left[(1-\alpha)\left(1+E_{0}\right)+B_{0}\right]-\left(B_{0} D_{b}-\alpha R \psi\left(1+E_{0}\right)\right)-D_{u}$. For $S>\bar{S}$, it is a dominant strategy for fund managers not to roll over. Since $0<\underline{S}<\bar{S}<\infty$ for any funding choices, both dominance regions are well defined.

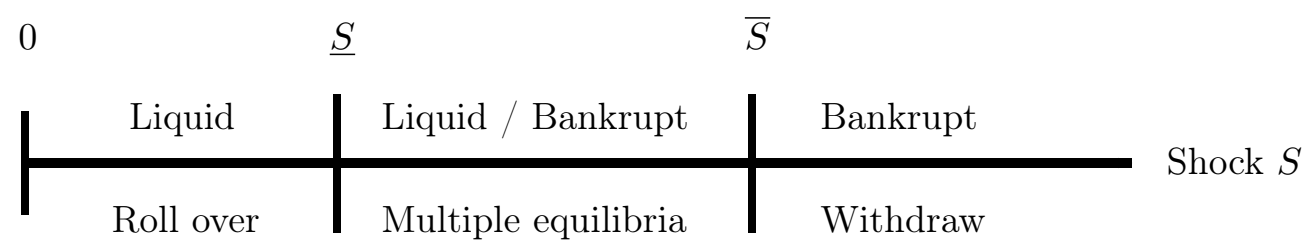

Figure 1: Tripartite classification of the shock

Unlike the banker, wholesale investors cannot observe the shock before it materializes. However, fund managers receive a noisy private signal, $x_{i}$, about the shock at $t=1$ upon which they base their rollover decisions. Specifically, they receive the signal $x_{i} \equiv S+\epsilon_{i}$, where $\epsilon_{i}$ is idiosyncratic noise drawn from a continuous distribution $G$ with support $[-\epsilon, \epsilon]$, for $\epsilon>$ 0 . The idiosyncratic noise is independent of the shock and is independently and identically distributed across fund managers. Such incomplete information facilitates a unique solution to the coordination game between fund managers (Morris and Shin, 2003).

Table 3 summarizes the timeline of events. 


\begin{tabular}{lll}
\hline$t=0$ & $t=1$ & $t=2$ \\
\hline 1. Unsecured debt issuance & 1. Banker observes shock & 1. Investment matures \\
2. Investment & 2. Dynamic replenishment & 2. Shock materializes \\
3. Asset encumbrance & 3. Private signals about shock & 3. Banker honors debts \\
4. Secured debt issuance & 4. Unsecured debt withdrawals & \\
5. Additional investment & & \\
\hline
\end{tabular}

Table 3: Timeline of events

\section{Equilibrium}

We solve the model backwards. We start by analyzing the rollover decisions of fund managers at $t=1$, for a given amount and face value of funding and level of asset encumbrance. Next, we study the optimal choices of the banker at $t=0$. In the secured funding round, the banker chooses the amount of covered bond funding, $B_{0}$, the level of asset encumbrance, $\alpha$, and the face value of covered bonds, $D_{b}$, to maximize the expected value of bank equity, subject to the participation constraint of infinitely risk-averse investors. In the unsecured funding round, the banker chooses the face value of unsecured funding, $D_{u}$, to maximize the expected value of equity, subject to the participation constraint of risk-neutral investors.

\subsection{Rollover risk of unsecured debt}

Under imperfect information about the shock, there is a unique Bayesian equilibrium in each unsecured debt rollover subgame at $t=1$ summarized in Proposition 1. In what follows, we consider the limit case of vanishing private noise, $\epsilon \rightarrow 0$.

Proposition 1. Bankruptcy threshold. There exists a unique Bayesian equilibrium in each unsecured debt rollover subgame. It is characterized by a bankruptcy threshold

$$
S^{*} \equiv R\left[B_{0}+(1-\alpha)\left(1+E_{0}\right)\right]-\kappa D_{u}-\left(B_{0} D_{b}-\alpha R \psi\left(1+E_{0}\right)\right) \in(\underline{S}, \bar{S}),
$$


where $\kappa \equiv 1+\gamma\left(\frac{1}{\psi}-1\right) \in\left(1, \frac{1}{\psi}\right)$. Fund managers roll over unsecured debt if and only if $S \leq S^{*}$ such that bankruptcy occurs if and only if $S>S^{*}$.

Proof. See Appendix A.

Coordination failure in the unsecured funding market is measured by $\kappa-1$. It increases in the conservativeness of fund managers and decreases in the liquidation value of assets. In the former case, more conservative managers choose to roll over less often and cause costly liquidation. In the latter case, higher liquidation values decrease the strategic complementarity among fund managers.

Corollary 1 summarizes the partial impact of funding choices on the bankruptcy threshold.

Corollary 1. The bankruptcy threshold $S^{*}$ decreases in asset encumbrance and in the face value of secured and unsecured funding but increases in the amount of covered bond funding:

$\frac{\partial S^{*}}{\partial \alpha}=-R(1-\psi)\left(1+E_{0}\right)<0, \quad \frac{\partial S^{*}}{\partial D_{b}}=-B_{0}<0, \quad \frac{\partial S^{*}}{\partial D_{u}}=-\kappa<0, \quad \frac{\partial S^{*}}{\partial B_{0}}=R-D_{b} \geq 0$.

Proof. See Appendix A.

The intuition is as follows. First, greater asset encumbrance reduces both the amount of unencumbered assets available to meet withdrawals by fund managers and the net claim of covered bond holders under dual recourse. The overall effect of greater encumbrance is that fund managers withdraw deposits for a larger range of shocks. Second, more costly secured funding raises the dual recourse claims of covered bond holders. It induces withdrawals of unsecured debt at $t=1$ to prevent a dilution of their claims. Third, more costly unsecured funding exacerbates the degree of strategic complementarity among fund managers, which induces them to withdraw unsecured debt more often. Fourth, more secured funding increases both the amount of unencumbered assets and the claims of covered bond holders under dual recourse. The former effect dominates since $D_{b} \leq R$. 


\subsection{Secured funding and asset encumbrance}

We derive the banker's objective function in the secured round of funding, taking as given the face value of unsecured funding. For values of the shock below the bankruptcy threshold, $S \leq S^{*}$, the equity value is positive and equal to the value of investments net of the shock and total debt repayments to investors, $E(S)=R\left(1+E_{0}+B_{0}\right)-S-B_{0} D_{b}-D_{u}>0$. For shocks above the threshold, the value of equity is zero because of limited liability.

We derive the participation constraint of infinitely risk-averse investors. The expected utility from holding a covered bond is no smaller than the return on storage. Each covered bond has face value $D_{b}$, backed by an equal share of the liquidated cover pool, $\alpha \psi R \frac{1+E_{0}}{B_{0}}$, along with dual recourse on the bank's unencumbered assets in bankruptcy. If the shock wipes out unencumbered assets, $S>S_{\max } \equiv R\left[B_{0}+(1-\alpha)\left(1+E_{0}\right)\right]$, bankruptcy occurs and dual recourse has zero value. However, covered bonds remain safe because of bankruptcyremoteness. ${ }^{9}$ Taken together, the banker's problem in the secured funding round is

$$
\begin{gathered}
\max _{\left\{\alpha, B_{0}, D_{b}\right\}} \pi \equiv \int E(S) d F(S)=F\left(S^{*}\right)\left[R\left(1+E_{0}+B_{0}\right)-D_{u}-B_{0} D_{b}\right]-\int_{0}^{S^{*}} S d F(S) \\
\text { s.t. } r \leq \min \left\{D_{b}, \frac{\alpha R \psi\left(1+E_{0}\right)}{B_{0}}\right\} .
\end{gathered}
$$

Critically, the dual recourse provision is never called upon in equilibrium. This result is consistent with Wandschneider (2014), who notes that the dual recourse clause has never been invoked in the history of covered bonds.

Lemma 1. Bank funding channel. If risk-averse investors are abundant, $\omega \geq \underline{\omega}$, the face value of covered bonds is $D_{b}^{*}=r$ and the issuance volume is $B_{0}^{*}=\alpha^{*}\left(1+E_{0}\right) \psi z$, where the relative return is $z \equiv R / r$.

\footnotetext{
${ }^{9}$ In general, the value of the covered bond to an infinitely risk-averse investor is

$\min _{S}\left\{D_{b}, \alpha R \psi \frac{1+E_{0}}{B_{0}}+\max \left\{0, \frac{D_{b}}{B_{0} D_{b}+\left(1-\ell^{*}(S)\right) D_{u}} \psi\left(R\left[B_{0}+(1-\alpha)\left(1+E_{0}\right)\right]-S-\frac{\ell^{*}(S) D_{u}}{\psi}\right)\right\}\right\}$, where $\ell^{*}(S)=\mathbb{I}_{S>S^{*}}$. At $S=S_{\max }$, it is a strictly dominant action to withdraw, $\ell^{*}\left(S_{\max }\right)=1$.
} 
Proof. See Appendix B.

Lemma 1 states the bank funding channel. Encumbering more assets allows the banker to issue more covered bonds. As more secured funding is attracted, the banker expands its balance sheet via more investment and increases its expected equity value. By encumbering all existing assets, the banker can, at most, issue $\underline{\omega} \equiv \psi z\left(1+E_{0}\right)$ of covered bonds. If the mass of risk-averse investors exceeds $\underline{\omega}$, then the total issuance volume is absorbed.

Lemma 2. Risk-concentration channel. Encumbering more assets increases fragility:

$$
\frac{d S^{*}}{d \alpha}=\frac{\partial S^{*}}{\partial \alpha}+\frac{\partial S^{*}}{\partial B_{0}^{*}} \frac{d B_{0}^{*}}{d \alpha}=-R(1-\psi z)\left(1+E_{0}\right)<0
$$

Proof. See Appendix B.

Lemma 2 states the risk-concentration channel. Issuing covered bonds concentrates the shock on unsecured debt holders. Dynamic replenishment of the cover pool makes covered bonds effectively senior to unsecured debt. While greater asset encumbrance leads to more secured funding that increases unencumbered assets, the effect of dynamic replenishment dominates because of over-collateralization. Therefore, the net effect of greater asset encumbrance is a higher incidence of unsecured debt runs on the bank (higher bank fragility).

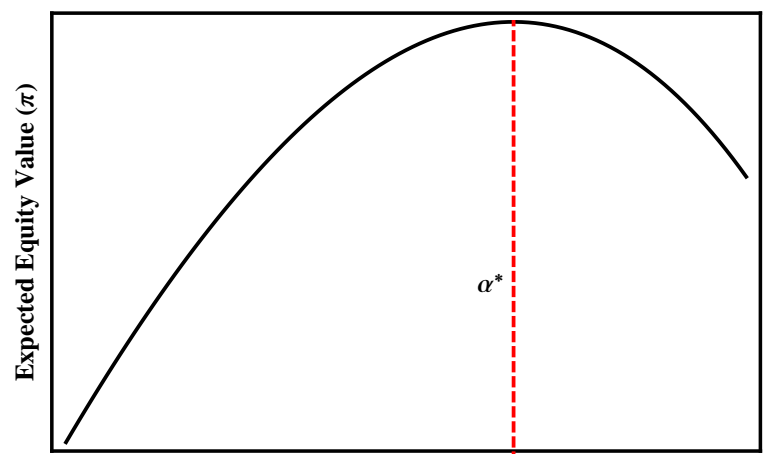

Level of Asset Encumbrance $(\alpha)$

Figure 2: Expected value of equity as a function of the level of asset encumbrance. In this example, we set $R=1.1, r=1, E_{0}=1.1, \psi=0.7, \gamma=0.025, D_{u}=1.05$, and the balance sheet shock follows an exponential distribution with rate $\lambda=1.1$. 
As Figure 2 illustrates, the banker's optimal choice of asset encumbrance takes both the bank funding and the risk-concentration channels into account.

Proposition 2. Optimal asset encumbrance. There exists a unique privately optimal level of asset encumbrance $\alpha^{*} \in[0,1]$. There exist unique bounds on investment profitability $\underline{R}$ and $\bar{R}$ such that the encumbrance level is interior for $\underline{R}<R<\bar{R}$ and implicitly given by:

$$
\frac{F\left(S^{*}\left(\alpha^{*}\right)\right)}{f\left(S^{*}\left(\alpha^{*}\right)\right)}=\frac{(1-\psi z)}{\psi(z-1)}\left[(\kappa-1) D_{u}+\alpha^{*}(1-\psi) R\left(1+E_{0}\right)\right]
$$

Proof. See Appendix C.

To obtain an interior solution, we require two conditions. First, the expected profit function satisfies $\left.\frac{d \pi}{d \alpha}\right|_{\alpha=0}>0$, whereby the banker is strictly better off encumbering some assets. This condition yields the lower bound on asset profitability $\underline{R}$. Second, the expected profit function satisfies $\left.\frac{d \pi}{d \alpha}\right|_{\alpha=1}<0$, whereby the banker is strictly better off not encumbering all assets. This condition yields the upper bound on asset profitability $\bar{R}$.

Focusing on the interior solution, Proposition 3 describes how the privately optimal level of asset encumbrance varies with parameters and the face value of unsecured funding.

Proposition 3. Determinants of asset encumbrance. The privately optimal level of asset encumbrance $\alpha^{*}$ increases in the liquidation value $\psi$. It decreases in the conservatism of fund managers $\gamma$, the return on storage $r$, and the face value of unsecured funding $D_{u}$. If the return on storage satisfies $r<\bar{r}$, then $\alpha^{*}$ increases in initial bank capital $E_{0}$ and in investment profitability $R$. If the shock distribution $\widetilde{F}$ stochastically dominates $F$ according to the reverse hazard rate, the corresponding levels of asset encumbrance satisfy $\widetilde{\alpha}^{*} \geq \alpha^{*}$.

Proof. See Appendix D.

These results highlight the trade-off between profitability and fragility associated with asset encumbrance. A higher liquidation value lowers the degree of strategic complementarity 
among fund managers, for any given level of encumbrance. Withdrawals by some managers, and the resulting liquidation of assets, cause less damage to others. Therefore, the bank is less fragile and bankruptcy occurs for a smaller range of shocks. As a result, the banker encumbers more assets to increase investment and the expected equity value. Overall, there are fewer but more-liquid unencumbered assets on the bank's balance sheet. By the same logic, a decrease in the face value of unsecured debt increases the level of asset encumbrance.

As the degree of conservatism increases, fund managers roll over less often and the bank is more fragile, for any given level of encumbrance. The banker responds to heightened fragility in a precautionary manner by reducing the level of encumbrance and forgoing profitable investment via the issuance of covered bonds, in return for more stable unsecured debt. A higher outside option for investors increases the face value of covered bonds and correspondingly decreases their issuance volume, which reduces unencumbered assets and heightens fragility, for any given level of encumbrance. As before, the banker responds by reducing encumbrance. Similarly, a more favorable distribution of the balance sheet shock, $\widetilde{F}$, reduces fragility for a given encumbrance level and induces the banker to encumber more.

An increase in initial bank capital has the following effects. First, greater capital allows the banker to scale up the balance sheet, encumber more assets, and issue more covered bonds. Second, greater capital also allows for the absorption of higher losses, which has two opposing effects. On the one hand, this reduces bank fragility and induces greater asset encumbrance. On the other hand, the expected equity value is lower, which reduces encumbrance. If the return on storage is sufficiently low relative to the return on investment, the bank funding channel is sufficiently strong and the banker unambiguously encumbers more assets. Likewise, an increase in investment profitability leads to a similar ambiguous effect on the privately optimal level of asset encumbrance. The same sufficient condition on the upper bound of the return on storage arises. Tighter predictions on how private choices of asset encumbrance vary with bank capital and investment profitability can be obtained for specific distributions of the balance sheet shock. 
Corollary 2. Uniform shock distribution. Suppose the shock is uniformly distributed, $S \sim \mathcal{U}\left[0, R\left(1+E_{0}+\omega\right)\right]$. If interior, the privately optimal level of asset encumbrance is

$$
\alpha^{*}=\frac{R\left(1+E_{0}\right) \psi(z-1)-(\kappa-1+\psi(z-\kappa)) D_{u}}{R\left(1+E_{0}\right)\left[\psi^{2}(2-z)-2 z+1\right]}
$$

which ambiguously increases in initial bank capital and in investment profitability.

Proof. See Appendix D.

\subsection{Unsecured funding}

Having established the equilibrium in the secured funding round, we turn to the unsecured funding round. We solve for the equilibrium face value of unsecured funding.

Figure 3 shows how the repayment of unsecured debt depends on the size of the shock. If the bank is solvent, $S<S^{* *} \equiv S^{*}\left(\alpha^{*}\right)$, unsecured debt holders receive the promised payment $D_{u}$. For intermediate shocks, they receive an equal share of the liquidated unencumbered assets. Investors receive zero by limited liability for a large shock, $S>$ $S_{\max }^{*} \equiv S_{\max }\left(\alpha^{*}\right)=R\left(1+E_{0}\right)\left[1-\alpha^{*}(1-\psi z)\right]$. In sum, for small and intermediate shocks, the unsecured debt claim pays $\min \left\{D_{u}, \psi\left(S_{\text {max }}^{*}-S\right)\right\}$.

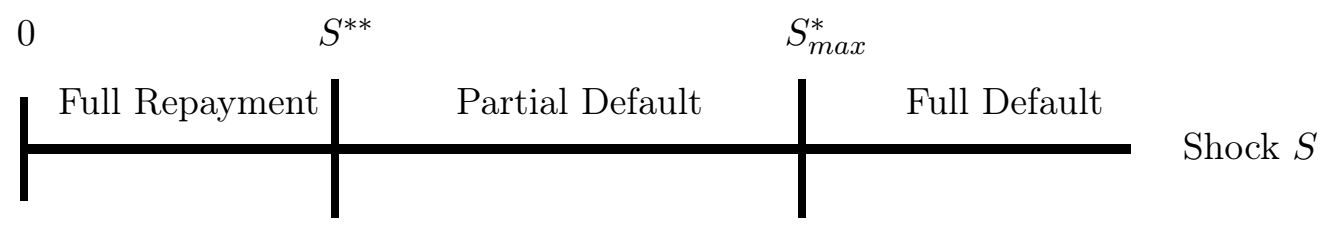

Figure 3: The size of the shock determines the payment to unsecured debt holders.

In the unsecured funding round, the banker sets the face value of unsecured debt $D_{u}$ to maximize the expected value of equity, subject to the participation of risk-neutral investors. The expected equity value decreases in the face value of unsecured debt, $d \pi\left(\alpha^{*}\right) / d D_{u}=$ 
$\left.\left.-F\left(S^{* *}\right)-\kappa f\left(S^{* *}\right)\right) E\left(S^{* *}\right)\right)<0$. Hence, the banker chooses the smallest face value consistent with satisfying the participation constraint of risk-neutral investors:

$$
r=F\left(S^{* *}\right) D_{u}^{*}+\psi \int_{S^{* *}}^{S_{\max }^{*}}\left[S_{\max }^{*}-S\right] d F(S) \equiv V\left(D_{u}^{*}\right),
$$

where $V\left(D_{u}\right)$ is the value of the unsecured debt claim when the face value is $D_{u}$.

Proposition 4. Unsecured funding. There exists a unique face value of unsecured debt, $D_{u}^{*}>r$, if the investment return is sufficiently low, $R \leq \tilde{R}$, and if investors always accept unsecured debt when promised the investment return.

Proof. See Appendix E.

The first sufficient condition, $R \leq \tilde{R}$, ensures that the value of the debt claim increases in the face value of unsecured debt, $\frac{d V}{d D_{u}}>0$, so, at most, one solution $D_{u}^{*}$ exists. The second sufficient condition ensures the existence of $D_{u}^{*}$. Since $V\left(D_{u}=r\right)<r$, a solution $D_{u}^{*}$ exists if risk-neutral investors accept unsecured debt when promised the investment return, $V\left(D_{u}=R\right)>r$. Since default occurs with positive probability, the face value is $D_{u}^{*}>r$.

Corollary 3. Secured funding is cheaper than unsecured funding, $D_{b}^{*}=r<D_{u}^{*}$.

Corollary 3 follows immediately from comparing the results of Proposition 4 and Lemma 1. While dynamic replenishment and bankruptcy-remoteness make covered bonds a cheap source of funding, these features also make unsecured funding more costly.

Proposition 5. Tail risk and unsecured funding costs. Consider two distributions, $F$ and $\hat{F}$. If $\hat{F}$ first-order stochastically dominates $F$ in that $\hat{F}(S)=F(S)$ for $S \leq R\left(1+E_{0}+\right.$ $\omega)-\kappa r$ and $\hat{F}(S)<F(S)$ for $R\left(1+E_{0}+\omega\right)-\kappa r<S<R\left(1+E_{0}+\omega\right)$, then $\hat{D}_{u}^{*}<D_{u}^{*}$.

Proof. See Appendix F. 
Proposition 5 links tail risk to the face value of unsecured funding. Both distributions, $F$ and $\hat{F}$, assign the same probability to small and intermediate shocks, $S \leq R\left(1+E_{0}+\omega\right)-$ $\kappa r>S^{*}$, so the privately optimal encumbrance choice is the same, $\hat{\alpha}^{*}=\alpha^{*}$. However, these distributions differ for large shocks, which are less likely under $\hat{F}$ than under $F$ (lower tail risk). Under $\hat{F}$, unencumbered assets have a higher expected liquidation value in bankruptcy, inducing risk-neutral investors to accept a lower face value of unsecured debt.

\section{Public Guarantees}

In many jurisdictions, unsecured debt holders enjoy the benefits of explicit (or perhaps implicit) public guarantee schemes. Such schemes, which usually apply to retail deposits, often extend to unsecured wholesale depositors during times of crisis. But deposit insurance schemes do not typically incorporate the effects of collateralized bank balance sheets. A bank with a large deposit base may, therefore, find it optimal to issue secured funding in order to shift risks to the deposit guarantee scheme. Guaranteed unsecured debt holders do not factor in the consequences of increased asset encumbrance and the benefits of public guarantees are externalized. As a result, prudential safeguards are required to limit excessive encumbrance and bank fragility. These safeguards include caps on asset encumbrance (Australia and New Zealand), ceilings on the amount of secured funding (Canada and the United States), and the inclusion of encumbrance levels in deposit insurance premiums (Canada).

Our model provides a natural framework with which to examine these normative issues. We focus on the secured funding round at $t=0$ and show how prudential safeguards - a cap on asset encumbrance or, equivalently, on covered bond issuance; a surcharge for asset encumbrance; and minimum capital requirements — establish constrained efficiency.

Let a fraction $0<m<1$ of unsecured debt be guaranteed and the guarantor (e.g., the government) be deep-pocketed. Guaranteed debt holders have no need to withdraw at $t=1$. If $D_{g}$ denotes the face value of guaranteed debt, the bankruptcy condition becomes 
$R\left[(1-\alpha)\left(1+E_{0}\right)+B_{0}\right]-S-\frac{\ell(1-m) D_{u}}{\psi}<(1-\ell)(1-m) D_{u}+m D_{g}+\left[D_{b} B_{0}-\alpha R \psi\left(1+E_{0}\right)\right]$.

The value of unencumbered assets at $t=2$ is again the left-hand side of equation (8). At $t=1$, a fraction $\ell$ of the $(1-m)$ non-guaranteed unsecured debt is withdrawn, resulting in costly liquidation. Therefore, guarantees reduce the amount of liquidation that the banker has to make in order to meet interim-date withdrawals. The remaining non-guaranteed unsecured debt is rolled over, so the banker at $t=2$ must meet these, $(1-\ell)(1-m) D_{u}$, along with guaranteed unsecured claims, $m D_{g}$, and the claims of covered bond holders due to dual recourse. Applying the global games method, the bankruptcy threshold changes to

$$
S_{m}^{*}=R\left[(1-\alpha)\left(1+E_{0}\right)+B_{0}\right]-m D_{g}-(1-m) \kappa D_{u}-\left[D_{b} B_{0}-\alpha R \psi\left(1+E_{0}\right)\right] .
$$

We assume that the face value of non-guaranteed unsecured debt exceeds that of guaranteed unsecured debt, $D_{u} \geq D_{g} \cdot{ }^{10}$ As a result, $\kappa D_{u}>D_{g}$, and the bankruptcy threshold increases in the coverage of the guarantee, $\partial S_{m}^{*} / \partial m>0$. This reduction in the incidence of runs is a consequence of the lower cost and greater stability of guaranteed funding, since guaranteed unsecured funding is not associated with rollover risk, $\kappa>1$.

The equilibrium in the secured funding market at $t=0$ yields $D_{b}^{*}=r$ and $B_{0}^{*}=$ $\alpha z \psi\left(1+E_{0}\right)$, as before. The risk-concentration channel remains unchanged, $d S_{m}^{*} / d \alpha=$ $-R(1-z \psi)\left(1+E_{0}\right)<0$. In establishing the privately optimal choice of asset encumbrance, $\alpha_{m}^{*}$, the banker ignores the guarantee cost but takes into account the stabilizing influence of guaranteed unsecured debt on rollover behavior. The banker's problem can be reduced to:

$$
\begin{aligned}
\max _{\alpha} \pi_{m} \equiv & F\left(S_{m}^{*}\right)\left[R\left(1+E_{0}\right)(1+\alpha(z-1) \psi)-m D_{g}-(1-m) D_{u}\right]-\int_{0}^{S_{m}^{*}} S d F(S) \\
& \text { s.t. } \quad S_{m}^{*}=R\left(1+E_{0}\right)[1-\alpha(1-\psi z)]-m D_{g}-(1-m) \kappa D_{u} .
\end{aligned}
$$

\footnotetext{
${ }^{10}$ While this result arises endogenously at the unsecured funding round, our focus on the secured funding round keeps the normative analysis simple and offers sharp predictions.
} 
Proposition 6 states the privately optimal choice of asset encumbrance with public guarantees. We focus on the interior solution, which arises under similar constraints on investment profitability as in Proposition 2.

\section{Proposition 6. Public guarantees and the privately optimal encumbrance level.}

There exists a unique privately optimal level of asset encumbrance with public guarantees. An interior solution $\alpha_{m}^{*} \in(0,1)$ is implicitly given by:

$$
\frac{F\left(S_{m}^{*}\left(\alpha_{m}^{*}\right)\right)}{f\left(S_{m}^{*}\left(\alpha_{m}^{*}\right)\right)}=\frac{1-\psi z}{\psi(z-1)}\left[(\kappa-1)(1-m) D_{u}+\alpha_{m}^{*}(1-\psi) R\left(1+E_{0}\right)\right]
$$

An increase in the coverage of the guarantee induces greater asset encumbrance, $\frac{d \alpha_{m}^{*}}{d m}>0$.

Proof. See Appendix G.

The intuition for Proposition 6 relates to the cost and stability of funding. For any given level of encumbrance, as the fraction of guaranteed unsecured debt increases, there is less rollover risk, and the bankruptcy threshold $S_{m}^{*}$ increases, which reduces the range of shocks to which the bank is susceptible. Consequently, the banker encumbers more assets in order to expand the balance sheet and to increase the expected value of bank equity.

Unlike the banker, the planner accounts for the expected costs of guaranteeing a fraction $m$ of unsecured debt, denoted by $C$. Suppose that guaranteed debt is senior to non-guaranteed claims. In bankruptcy, the value of unencumbered assets is $\psi\left(S_{\max }-S\right)$. Since the face value of guaranteed debt is $m D_{g}$, the bank has sufficient resources to service guaranteed debt as long as $\psi\left(S_{\max }-S\right) \geq m D_{g}$. We can express this condition as an upper bound on the balance sheet shock, $S \leq S_{\max }-\frac{m D_{g}}{\psi} \cdot{ }^{11}$ Partial default, and thus costs to the guarantor, occur for $S_{\max }-m D_{g} / \psi<S \leq S_{\max }$. Full default occurs for larger shocks, $S_{\max }<S$. Taken together, the expected cost to the guarantor is:

\footnotetext{
${ }^{11}$ To ensure that the guarantor always repays guaranteed debt if solvent, we impose $S_{\max }-\frac{m D_{g}}{\psi}>S_{m}^{*}$, for which an upper bound on the fraction of guaranteed debt, $m<\bar{m} \equiv \frac{\psi+\gamma(1-\psi)}{1+\gamma(1-\psi)} \in(0,1)$, suffices.
} 


$$
C \equiv \int_{S_{\max }-\frac{m D_{g}}{\psi}}^{S_{\max }}\left[m D_{g}-\psi\left(S_{\max }-S\right)\right] d F(S)+m D_{g} \int_{S_{\max }}^{\infty} d F(S)
$$

Lemma 3. Guarantee cost. The expected cost to the guarantor increases in both the level of asset encumbrance and in the fraction of guaranteed unsecured debt; it is also weakly convex in the level of encumbrance and has a positive cross-derivative:

$$
\frac{\partial C}{\partial \alpha}>0, \quad \frac{\partial C}{\partial m}>0, \quad \frac{\partial^{2} C}{\partial \alpha^{2}} \geq 0, \quad \frac{\partial^{2} C}{\partial \alpha \partial m}>0
$$

Proof. See Appendix H.

Lemma 3 summarizes the key features of the cost of guaranteeing unsecured debt. First, as more assets are encumbered, the upper bound $S_{\max }$ decreases, so the guarantor pays out for a larger range of shocks. Second, an increase in the fraction of guaranteed debt

has two effects: (i) a decrease in the lower bound $S_{\max }-\frac{m D_{g}}{\psi}$ and thereby an increase in the range of shocks over which the guarantee is paid; and (ii) an increase in the coverage of the guarantee. Third, greater coverage increases the expected costs of the guarantee.

The planner chooses the level of asset encumbrance to maximize the expected equity of the banker net of the expected costs of the guarantor (investors break even). Formally, the constrained efficient level of asset encumbrance, $\alpha_{P}$, solves the planner's problem:

$$
\begin{aligned}
\max _{\alpha} W \equiv & \pi_{m}(\alpha)-(1+\xi) C(\alpha) \\
& \text { s.t. } \quad S_{m}^{*}=R\left(1+E_{0}\right)[1-\alpha(1-\psi z)]-m D_{g}-(1-m) \kappa D_{u},
\end{aligned}
$$

where $\xi \geq 0$ measures the dead-weight loss of raising the funds to back the guarantee, for example, due to distortionary taxation. We again focus on interior solutions. 
Proposition 7. Public guarantees and constrained inefficiency. The privately optimal level of asset encumbrance is excessive, $\alpha_{m}^{*}>\alpha_{P}$. This gap increases in the coverage of

the guarantee, $\frac{d\left(\alpha_{m}^{*}-\alpha_{P}^{*}\right)}{d m}>0$, and in the dead-weight loss, $\frac{d\left(\alpha_{m}^{*}-\alpha_{P}\right)}{d \xi}>0$. The privately optimal level of bank fragility is excessive, $S_{m}^{* *} \equiv S_{m}^{*}\left(\alpha_{m}^{*}\right)<S_{m}^{*}\left(\alpha_{P}\right) \equiv S_{P}$, and the gap increases in the coverage of the guarantee, $\frac{d\left(S_{P}-S_{m}^{* *}\right)}{d m}>0$ and in the dead-weight loss, $\frac{d\left(S_{P}-S_{m}^{* *}\right)}{d \xi}>0$.

\section{Proof. See Appendix I.}

The expected cost of the guarantee drives a wedge between the privately optimal and constrained efficient levels of asset encumbrance. Greater coverage makes a larger proportion of unsecured bank funding cheap and stable, pushing up the privately optimal level of encumbrance. However, the expected cost of the guarantee also increases, so the wedge increases in coverage. Moreover, a higher dead-weight loss of the funds that back the guarantee reduces the constrained efficient level of encumbrance without affecting the privately optimal level. Finally, the excessive fragility of the bank and the associated comparative statics are a direct consequence, since a higher level of encumbrance leads to more fragility.

Proposition 7 clarifies why policy-makers (e.g., CGFS, 2013) have emphasized the importance of prudential safeguards to mitigate the risks of heavy asset encumbrance. In what follows, we consider three schemes that a regulator can introduce before the secured funding round at $t=0$ in order to influence the banker's choice of asset encumbrance. These include (i) caps on asset encumbrance (or, equivalently, on covered bond issuance); (ii) minimum capital requirements; and (iii) surcharges based on asset encumbrance. Let $\alpha_{m}^{* *}$ denote the constrained privately optimal level of asset encumbrance.

We start with the cap on asset encumbrance. The formal constrained problem for the banker is given in (10) with the additional constraint of an encumbrance limit, $\alpha \leq \bar{\alpha}$.

Proposition 8. Caps on asset encumbrance. A cap on asset encumbrance $\alpha<\bar{\alpha} \equiv \alpha_{P}$ attains the constrained efficient allocation $\left(\alpha_{P}, S_{P}\right)$ as the constrained private optimum. 
Proof. See Appendix J.

The privately optimal level of encumbrance is constrained efficient, $\alpha_{m}^{* *}=\alpha_{P}$, which also results in a constrained efficient level of bank fragility, $S_{m}^{* *}=S_{P}$. Intuitively, the bank funding channel still dominates the risk-concentration channel at $\alpha=\alpha_{P}$, so the banker wishes to encumber more assets but is limited by the regulatory cap, as shown in Figure 4.

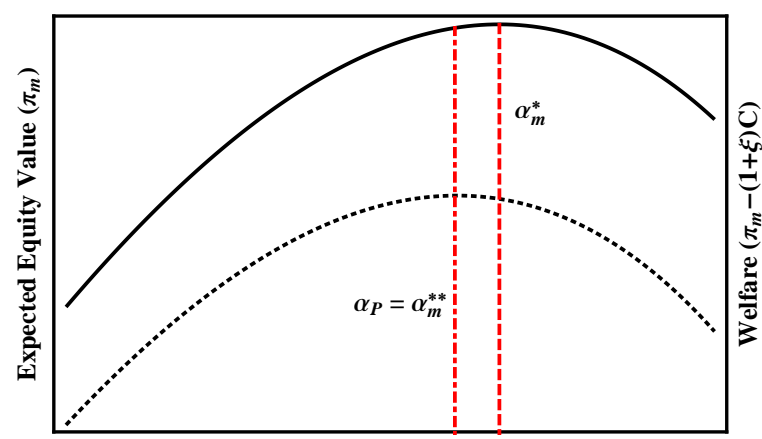

Level of Asset Encumbrance ( $\alpha$ )

Figure 4: Expected value of equity and welfare as functions of the level of asset encumbrance. In this example, we set $R=1.1, r=1, E_{0}=1.1, \psi=0.7, \gamma=0.025, m=0.2, D_{u}=1.05$, $D_{g}=1.0, \xi=0.01$, and the shock follows an exponential distribution with rate $\lambda=1.1$.

Second, we consider minimum capital requirements. Let $e$ denote the bank's unweighted capital ratio at $t=0$. It is given by the ratio of the bank's own funds, $E_{0}$, and total assets, $1+E_{0}+B_{0}$. Using the equilibrium relation $B_{0}=\alpha z \psi\left(1+E_{0}\right)$, we can express the bank's capital ratio as a function of the asset encumbrance level and parameters:

$$
e(\alpha) \equiv \frac{E_{0}}{\left(1+E_{0}\right)(1+\alpha \psi z)}
$$

whereby greater asset encumbrance expands the balance sheet with debt-funded investment and therefore strictly decreases the capital ratio, $\frac{d e}{e \alpha}<0$.

Proposition 9. Minimum capital requirements. A minimum capital ratio, $e(\alpha) \geq \underline{e} \equiv$ $e\left(\alpha_{P}\right)$, attains the constrained efficient allocation as the constrained private optimum.

Proof. See Appendix J. 
Encumbering more assets attracts more covered bond funding and thus allows the banker to invest more, for a constant amount of initial capital. Therefore, by imposing a lower bound $\underline{e}$ on the bank's capital ratio, the regulator indirectly influences the privately chosen level of asset encumbrance. In particular, setting $\underline{e} \equiv e\left(\alpha_{P}\right)$, the constrained efficient level of asset encumbrance is achieved, also resulting in the constrained efficient level of bank fragility. In sum, if appropriately tailored, both a cap on asset encumbrance and a minimum capital ratio attain the constrained efficient level of asset encumbrance and bank fragility. This equivalence result requires encumbered assets to have positive risk weights. If encumbered assets had zero risk weights, however, the capital ratio would be insensitive to encumbrance.

Third, we consider the surcharge for encumbering assets $\Delta(\alpha)$ paid by the banker at $t=0$. This surcharge is similar to the deposit insurance premium paid to a deposit insurance fund. We consider schedules for which there is no surcharge without encumbrance, $\Delta(0)=0$, and where the surcharge is weakly increasing in the level of asset encumbrance, $\Delta_{\alpha} \geq 0$. In contrast with the two previous regulatory tools, no additional constraint is added to the banker's problem, but the objective function and the bankruptcy threshold change:

$$
\begin{array}{cc}
\max _{\alpha} & F\left(S_{m}^{\Delta}\right)\left[R\left(\left(1+E_{0}\right)(1+\alpha(z-1) \psi)-\Delta(\alpha)\right)-m D_{g}-(1-m) D_{u}\right]-\int_{0}^{S_{m}^{\Delta}} S d F(S) \\
& \text { s.t. } \quad S_{m}^{\Delta} \equiv R\left[\left(1+E_{0}\right)(1-\alpha(1-\psi z))-\Delta(\alpha)\right]-m D_{g}-(1-m) \kappa D_{u}
\end{array}
$$

Since asset encumbrance surcharges impose a private cost on the banker, they may be a useful tool to curb the private incentives to excessively encumber assets. But there may be a tension between attaining the constrained efficient levels of encumbrance and fragility. Since surcharges reduce unencumbered assets, a higher surcharge can heighten bank fragility. Proposition 10 states two results about the design of asset encumbrance surcharges. 
Proposition 10. Asset encumbrance surcharge. There exists no continuous schedule of asset encumbrance surcharges that attains constrained efficiency. However, a schedule that is discontinuous at $\alpha_{P}$ can attain constrained efficiency.

Proof. See Appendix J.

Our first result suggests that surcharge schedules that are continuous, for example, linear in the level of asset encumbrance, cannot attain constrained efficiency. Intuitively, the surcharge must be sufficiently large for high levels of encumbrance, $\alpha>\alpha_{P}$, to deter excessive encumbrance and obtain the constrained efficient level of encumbrance. By continuity, the surcharge is also positive at $\alpha_{P}$. But this reduces unencumbered assets, heightens rollover risk, and adds to bank fragility. In other words, a continuous surcharge schedule can attain the constrained efficient level of asset encumbrance, but leads to excessive fragility.

Our second result suggests that constrained efficiency can be attained if the schedule of asset encumbrance surcharges has a discontinuity at $\alpha_{P}$. Consider the following example. No surcharge is applied as long as the level of asset encumbrance is less than $\alpha_{P}$. The bank can encumber assets up to the constrained efficient level without generating excessive fragility. To encumber assets beyond $\alpha_{P}$, however, the surcharge is so high that all unencumbered assets are wiped out. An unsecured debt run would follow, leading to bankruptcy where the bank's equity value is zero. As a result, the bank always chooses a level of encumbrance $\alpha_{m}^{* *} \leq \alpha_{P}$. Since the bank funding channel again dominates the risk-concentration channel for any $\alpha \in\left[0, \alpha_{P}\right]$, the banker's constrained privately optimal choice of asset encumbrance is $\alpha_{m}^{* *}=\alpha_{P}$ and results in the constrained efficient level of bank fragility. An example of a discontinuous surcharge schedule that achieves constrained efficiency is:

$$
\widehat{\Delta}(\alpha)=R\left(1+E_{0}+\omega\right) \mathbf{I}_{\alpha>\alpha_{\mathbf{P}}}
$$




\section{Conclusion}

This paper presents a model of bank funding with covered bonds and explores some implications for financial stability. To date, there has been no theoretical analysis of covered bonds and our work fills that gap. We find that asset encumbrance has two distinct balance sheet effects. First, covered bond issuance funds more profitable investment and increases the expected value of bank equity (bank funding channel). Second, because of dynamic replenishment of the cover pool, balance sheet shocks are asymmetrically shifted to unsecured debt holders, resulting in greater fragility (risk-concentration channel). The bank's choice of asset encumbrance balances this trade-off between profitability and fragility.

Covered bonds are safe assets and a cheap source of bank funding, but they exacerbate the riskiness and fragility of unsecured debt and render it more costly. This is a consequence of the replenishment and bankruptcy-remoteness of the cover pool that protects covered bond holders from balance sheet shocks and the dilution of their claims on cover pool assets in bankruptcy. Financial stability implications arise from the interaction of the rollover risk of unsecured debt and these two features of secured debt. Similar insights may apply to term repos, where safe harbor arrangements ensure bankruptcy-remoteness, and the right to substitute collateral or variation margins is economically similar to replenishment.

We derive normative implications about asset encumbrance in the context of guaranteed unsecured debt. The privately optimal level of encumbrance and bank fragility are excessive because the banker does not internalize the effect of encumbrance on the cost

of providing the guarantee. Absent prudential safeguards, banks have strong incentives to issue covered bonds in order to shift risk to the guarantor. Accordingly, proposals that emphasize covered bonds as a means of reviving mortgage finance need to be accompanied by prudential regulation.

We study three forms of regulation aimed at curbing excessive asset encumbrance by banks. First, a limit on the level of asset encumbrance may be imposed to restore 
constrained efficiency. This is consistent with measures taken in some jurisdictions such as Australia, Canada, New Zealand, and the United States. Second, since a bank's capital ratio is typically sensitive to the level of encumbrance, minimum capital requirements can be used to the same effect. Finally, we consider a surcharge for asset encumbrance paid to a deposit insurance fund or a contribution to a bailout fund. Our results suggest that a surcharge schedule has to be discontinuous in the level of asset encumbrance in order to restore constrained efficiency.

Our model generalizes to other settings. In practice, the mix of assets that back covered bonds are often heterogeneous, including mortgages and public debt. Following a balance sheet shock, the replenishment of the cover pool not only affects the amount of unencumbered assets, but also its risk profile. Since lower-risk assets would be swapped into the asset pool first, the risk-concentration effect would be exacerbated, raising fragility and reducing asset encumbrance. If investment was subject to decreasing marginal returns, the bank funding channel of asset encumbrance would be attenuated, reducing the incentives to issue covered bonds. Even with constant returns as in our model, however, the riskconcentration effect limits the private incentives to encumber assets.

Finally, our model assumes that the guarantor of the bank's unsecured debt is deeppocketed and always willing to pay. Doubts about the regulator in this regard could heighten the bank's fragility. This, in turn, may reduce the incentives of the bank to encumber assets and issue covered bonds. We leave a full treatment of this case for future work. 


\section{References}

Allen, F., E. Carletti, I. Goldstein, and A. Leonello (2015). Government guarantees and financial stability. CEPR Discussion Paper DP10560.

Beirne, J., L. Dalitz, J. Ejsing, M. Grothe, S. Manganelli, F. Monar, B. Sahel, M. Susec, J. Tapking, and T. Vong (2011). The impact of the Eurosystem's covered bond purchase programme on the primary and secondary markets. Occasional Paper Series 122, European Central Bank.

Bernanke, B. S. (2009). The future of mortgage finance in the United States. The B.E. Journal of Economic Analysis and Policy 9(3), 1-10.

Campbell, J. Y. (2013). Mortgage market design. Review of Finance 17(1), 1-33.

Carbo-Valverde, S., R. Rosen, and F. Rodriguez-Fernandez (2011). Are covered bonds a substitute for mortgage-backed securities? Federal Reserve Bank of Chicago WP 201114.

Carlsson, H. and E. van Damme (1993). Global games and equilibrium selection. Econometrica $61(5), 989-1018$.

CGFS (2013). Asset encumbrance, financial reform and the demand for collateral assets. Committee on the Global Financial System Publications No. 49, Bank for International Settlements, Basel.

Diamond, D. W. and P. H. Dybvig (1983). Bank runs, deposit insurance and liquidity. Journal of Political Economy 91, 401-419.

Diamond, D. W. and R. G. Rajan (2001). Liquidity risk, liquidity creation, and financial fragility: A theory of banking. Journal of Political Economy 109(2), 287-327.

Eisenbach, T., T. Keister, J. McAndrews, and T. Yorulmazer (2014). Stability of funding models: an analytical framework. FRBNY Economic Policy Review. 
Frankel, D., S. Morris, and A. Pauzner (2003). Equilibrium selection in global games with strategic complementarities. Journal of Economic Theory 108(1), 1-44.

Furletti, M. (2002). An overview of credit card asset-backed securities. Federal Reserve Bank of Philadelphia Payment Cards Center Discussion Paper.

Gai, P., A. G. Haldane, S. Kapadia, and B. D. Nelson (2013). Bank funding and financial stability. In A. Heath, M. Lilley, and M. Manning (Eds.), Liquidity and Funding Markets: Proceedings of the Reserve Bank of Australia Annual Conference, pp. 237-252.

Goldstein, I. and A. Pauzner (2005). Demand deposit contracts and the probability of bank runs. Journal of Finance 60(3), 1293-1327.

Goralnik, N. (2012). Bankruptcy-proof finance and the supply of liquidity. The Yale Law Journal 122, 460-506.

Greenbaum, S. I. and A. V. Thakor (1987). Bank funding modes: Securitization versus deposits. Journal of Banking and Finance 11(3), 379-401.

Keys, B., T. Mukherjee, A. Seru, and V. Vig (2010). Did securitization lead to lax screening? Evidence from subprime loans. Quarterly Journal of Economics 125(1), 307-362.

König, P., K. Anand, and F. Heinemann (2014). Guarantees, transparency and the interdependency between sovereign and bank default risk. Journal of Banking and Finance 45, $321-337$.

Leonello, A. (2016). Government guarantees and the two-way feedback between banking and sovereign debt crises. Mimeo.

Mastroeni, O. (2001). Pfandbrief-style products in Europe. In BIS Papers No. 5: The changing shape of fixed income markets: a collection of studies by central bank economists, pp. 44-66. Bank for International Settlements.

Matta, R. and E. Perotti (2015). Insecure debt. CEPR DP 10505. 
Modigliani, F. and M. Miller (1958). The cost of capital, corporation finance and the theory of investment. American Economic Review 48(3), 261-297.

Morris, S. and H. S. Shin (2003). Global games: theory and applications. In M. Dewatripont, L. P. Hansen, and S. J. Turnovsky (Eds.), Advances in Economics and Econometrics, pp. 56-114. Cambridge University Press.

Paulson, H. (2009). Statement on covered bond best practices. U.S. Treasury Press Center, July 28, 2009.

Prokopczuk, M., J. B. Siewert, and V. Vonhoff (2013). Credit risk in covered bonds. Journal of Empirical Finance 21, 102-120.

Prokopczuk, M. and V. Vonhoff (2012). Risk premia in covered bond markets. The Journal of Fixed Income 22(2), 19-29.

Purnanandam, A. (2011). Originate-to-distribute model and the subprime mortgage crisis. Review of Financial Studies 24, 1881-1915.

Rixtel, A. V., L. R. Gonzalez, and J. Yang (October 2015). The determinants of long-term debt issuance by European banks: evidence of two crises. BIS Working Paper 513.

Rochet, J.-C. and X. Vives (2004). Coordination failures and the Lender of Last Resort: was Bagehot right after all? Journal of the European Economic Association 2(6), 1116-1147.

Schwarcz, S. L. (2011). The conundrum of covered bonds. Business Lawyer 561(3), 561-586.

Soros, G. (2010). Reforming a broken mortgage system. www.politico.com.

Wandschneider, K. (2014). Lending to lemons: landschaft credit in eighteenth-century Prussia. In E. N. White, K. Snowden, and P. Fishback (Eds.), Housing and Mortgage Markets in Historical Perspective, Chapter 10, pp. 305-325. University of Chicago Press. 


\section{A Proof of Proposition 1}

In each rollover subgame, it is sufficient to establish the existence of a unique Bayesian equilibrium in threshold strategies for sufficiently precise private information. Morris and Shin (2003) show that only threshold strategies survive the iterated deletion of strictly dominated strategies; see also Frankel et al. (2003). Specifically, we consider the limiting case of vanishing private noise, $\epsilon \rightarrow 0$. Each fund manager $i$ uses a threshold strategy, whereby unsecured debt is rolled over if and only if the private signal suggests that the balance sheet shock is small, $x_{i}<x^{*}$. Hence, for a given realization $S \in[\underline{S}, \bar{S}]$, the proportion of fund managers who do not roll over debt is:

$$
\ell\left(S, x^{*}\right)=\operatorname{Prob}\left(x_{i}>x^{*} \mid S\right)=\operatorname{Prob}\left(\epsilon_{i}>x^{*}-S\right)=1-G\left(x^{*}-S\right) .
$$

A critical mass condition states that bankruptcy occurs when the balance sheet shock equals a threshold $S^{*}$, where the proportion of managers not rolling over is evaluated at $S^{*}$ :

$R\left[B_{0}+(1-\alpha)\left(1+E_{0}\right)\right]-S^{*}-\ell\left(S^{*}, x^{*}\right) \frac{D_{u}}{\psi}=\left(1-\ell\left(S^{*}, x^{*}\right)\right) D_{u}+\left(B_{0} D_{b}-\alpha R \psi\left(1+E_{0}\right)\right)$.

The posterior distribution of the balance sheet shock conditional on the private signal is derived using Bayes' rule. The indifference condition states that the manager who receives the critical signal $x_{i}=x^{*}$ is indifferent between rolling and not rolling over unsecured debt:

$$
\gamma=\operatorname{Pr}\left(S<S^{*} \mid x_{i}=x^{*}\right)
$$

Using the definition of the private signal $x_{j}=S+\epsilon_{j}$ of the indifferent fund manager, we can state the conditional probability as follows:

$$
\begin{aligned}
1-\gamma & =\operatorname{Pr}\left(S \geq S^{*} \mid x_{i}=x^{*}\right)=\operatorname{Pr}\left(S \geq S^{*} \mid x_{i}=x^{*}=S+\epsilon_{j}\right), \\
& =\operatorname{Pr}\left(x^{*}-\epsilon_{j} \geq S^{*}\right)=\operatorname{Pr}\left(\epsilon_{j} \leq x^{*}-S^{*}\right)=G\left(x^{*}-S^{*}\right) .
\end{aligned}
$$


The indifference condition implies that $x^{*}-S^{*}=G^{-1}(1-\gamma)$. Inserting the indifference condition into $\ell\left(S^{*}, x^{*}\right)$, the proportion of managers who do not roll over when the balance sheet shock is at the critical level $S^{*}$ is perceived by the indifferent manager to be:

$$
\ell\left(S^{*}, x_{i}=x^{*}\right)=1-G\left(x^{*}-S^{*}\right)=1-G\left(G^{-1}(1-\gamma)\right)=\gamma
$$

Therefore, the bankruptcy threshold $S^{*}$ stated in Proposition 1 follows. For vanishing private noise, the signal threshold also converges to this value, $x^{*} \rightarrow S^{*}$, allowing us to concentrate solely on the bankruptcy threshold. The partial derivatives of $S^{*}$ are immediate.

\section{B Proof of Lemma 1 and Lemma 2}

We prove that $B_{0}^{*}=\frac{\alpha^{*} \psi R\left(1+E_{0}\right)}{D_{b}^{*}}$ and $D_{b}^{*}=r$ in any equilibrium. We also derive the total effect of asset encumbrance on the bankruptcy threshold. We guess and verify that $D_{b}^{*}<R$. The partial derivatives of the objective function with respect to $B_{0}$ and $D_{b}$ are

$$
\begin{aligned}
\frac{\partial \pi}{\partial B_{0}} & =\left(R-D_{b}\right)\left[F\left(S^{*}\right)+f\left(S^{*}\right) E\left(S^{*}\right)\right]>0, \\
\frac{\partial \pi}{\partial D_{b}} & =-B_{0}\left[F\left(S^{*}\right)+f\left(S^{*}\right) E\left(S^{*}\right)\right]<0,
\end{aligned}
$$

where the equity value at $S^{*}$ is $E\left(S^{*}\right)=(\kappa-1) D_{u}+\alpha(1-\psi) R\left(1+E_{0}\right)>0$.

We prove $B_{0}^{*}=\frac{\alpha^{*} \psi R\left(1+E_{0}\right)}{D_{b}^{*}}$ by contradiction. First, suppose that $D_{b}^{*}>\frac{\alpha^{*} \psi R\left(1+E_{0}\right)}{B_{0}^{*}}$. Because of bankruptcy-remoteness, infinitely risk-averse investors value the covered bond claim at $\frac{\alpha^{*} \psi R\left(1+E_{0}\right)}{B_{0}^{*}}$, but the claims from dual recourse are worthless since bankruptcy occurs with positive probability. This violates the supposed optimality of $D_{b}^{*}$, since lowering the face value would raise the objective function $\left(\frac{\partial \pi}{\partial D_{b}}<0\right)$ without affecting the constraint. Contradiction. Thus, $D_{b}^{*} \leq \frac{\alpha^{*} \psi R\left(1+E_{0}\right)}{B_{0}^{*}}$. Second, suppose $D_{b}^{*}<\frac{\alpha^{*} \psi R\left(1+E_{0}\right)}{B_{0}^{*}}$. Infinitely riskaverse investors value the covered bond claim at $D_{b}$ since the bank is solvent with positive probability. This violates the supposed optimality of $B_{0}^{*}$, since raising the issuance volume of 
covered bonds would raise the objective function $\left(\frac{\partial \pi}{\partial B_{0}}>0\right)$ without affecting the constraint. Contradiction. Thus, $D_{b}^{*} \geq \frac{\alpha^{*} \psi R\left(1+E_{0}\right)}{B_{0}^{*}}$. Taken together, we have $B_{0}^{*}=\frac{\alpha^{*} \psi R\left(1+E_{0}\right)}{D_{b}^{*}}$. Thus, the problem of the banker reduces to

$$
\begin{aligned}
& \max _{\left\{\alpha, B_{0}\right\}} \pi\left(\alpha, B_{0}\right) \equiv F\left(S^{*}\right)\left[R\left(1+E_{0}+B_{0}\right)-\alpha R \psi\left(1+E_{0}\right)-D_{u}\right]-\int_{0}^{S^{*}} S d F(S) \\
& \text { s.t. } \\
& S^{*}=S^{*}\left(\alpha, B_{0}\right)=R\left[1+E_{0}+B_{0}\right]-\alpha R\left(1+E_{0}\right)-\kappa D_{u} \\
& r \leq \frac{\alpha \psi R\left(1+E_{0}\right)}{B_{0}} .
\end{aligned}
$$

Since $\frac{\partial \pi\left(\alpha, B_{0}\right)}{\partial \alpha}<0$, and $\frac{\partial \pi\left(\alpha, B_{0}\right)}{\partial B_{0}}>0$, the participation constraint of risk-averse investors binds in equilibrium, $B_{0}^{*}=\alpha^{*} \psi R\left(1+E_{0}\right)$, which yields $D_{b}^{*}=r<R$, verifying the supposition. This link between the encumbrance level and the amount of covered bond funding constitutes the bank funding channel. As a result, the bankruptcy threshold becomes $S^{*}(\alpha)=R\left(1+E_{0}\right)\left[1-\alpha\left(1-\frac{\psi R}{r}\right)\right]-\kappa D_{u}$. The total effect of encumbrance on this threshold is $\frac{d S^{*}(\alpha)}{d \alpha}=-R\left(1+E_{0}\right)\left(1-\frac{\psi R}{r}\right)<0$, which constitutes the risk-concentration channel.

\section{Proof of Proposition 2}

This proof continues from the proof of Lemma 1 and Lemma 2. Using $D_{b}^{*}=r$ and $B_{0}^{*}=$ $\alpha^{*} \frac{\psi R}{r}\left(1+E_{0}\right)$, we obtain a simple unconstrained optimization problem in which both the risk-concentration and the bank funding channels are taken into account:

$$
\begin{aligned}
& \max _{\alpha \in[0,1]} \pi(\alpha) \equiv F\left(S^{*}(\alpha)\right)\left[R\left(1+E_{0}\right)\left(1+\alpha \psi\left(\frac{R}{r}-1\right)\right)-D_{u}\right]-\int_{0}^{S^{*}(\alpha)} S d F(S) \\
& \text { s.t. } \\
& S^{*}(\alpha)=R\left(1+E_{0}\right)\left[1-\alpha\left(1-\frac{\psi R}{r}\right)\right]-\kappa D_{u} .
\end{aligned}
$$

Using the risk-concentration channel, the first and second derivatives of the objective function value with respect to the level of asset encumbrance are: 


$$
\begin{aligned}
\frac{1}{R\left(1+E_{0}\right)} \frac{d \pi}{d \alpha} \equiv & F\left(S^{*}\right) \psi\left(\frac{R}{r}-1\right)-\left(1-\frac{\psi R}{r}\right) f\left(S^{*}\right) E\left(S^{*}(\alpha)\right) \\
\frac{1}{R\left(1+E_{0}\right)} \frac{d^{2} \pi}{d \alpha^{2}} \equiv & \frac{d S^{*}(\alpha)}{d \alpha}\left[\psi\left(\frac{R}{r}-1\right) f\left(S^{*}(\alpha)\right)-\left(1-\frac{\psi R}{r}\right) f^{\prime}\left(S^{*}(\alpha)\right) E\left(S^{*}(\alpha)\right)\right] \\
& -\left(1-\frac{\psi R}{r}\right)(1-\psi) R\left(1+E_{0}\right) f\left(S^{*}(\alpha)\right)<0 .
\end{aligned}
$$

The sign of the second-order derivative is ensured by $f^{\prime} \leq 0$ and $\psi R<r$. Therefore, the objective function is globally concave and there exists at most one solution. If a solution exists, it is a (global) maximum. By continuity of the objective function $\pi$, and the closed set $[0,1]$ over which the banker maximizes, a solution $\alpha^{*}$ exists. This establishes the existence and uniqueness of a global maximum. We use the notation $\frac{d \pi}{d \alpha} \equiv \pi_{\alpha}$, etc.

We next study whether this solution is interior. First, we require $\alpha^{*}>0$. Rewriting $\left.\frac{d \pi}{d \alpha}\right|_{\alpha=0}>0$ and using $S^{*}(\alpha=0)=R\left(1+E_{0}\right)-\kappa D_{u}$ yields:

$$
\frac{F\left[R\left(1+E_{0}\right)-\kappa D_{u}\right]}{f\left[R\left(1+E_{0}\right)-\kappa D_{u}\right]}>\frac{\left(1-\frac{\psi R}{r}\right)}{\psi\left(\frac{R}{r}-1\right)}(\kappa-1) D_{u} .
$$

Focusing on the left-hand side of the expression above, we note that $\frac{F(.)}{f(.)}$ is strictly increasing. The argument itself increases in $R$. The right-hand side decreases in $R$. Consequently, $\alpha^{*}>0$ for any $R>\underline{R}$, which is implicitly defined by

$$
\frac{F\left[\underline{R}\left(1+E_{0}\right)-\kappa D_{u}\right]}{f\left[\underline{R}\left(1+E_{0}\right)-\kappa D_{u}\right]} \equiv \frac{\left(1-\frac{\psi \underline{R}}{r}\right)}{\psi\left(\frac{\underline{R}}{r}-1\right)}(\kappa-1) D_{u} .
$$

Note that $\underline{R} \in\left(r, \frac{r}{\psi}\right)$, since the right-hand side of condition (30) goes to positive infinity for $R \rightarrow r$ and to zero for $R \rightarrow \frac{r}{\psi}$, while the left-hand side is positive but finite.

Second, we require $\alpha^{*}<1$. Rewriting $\left.\frac{d \pi}{d \alpha}\right|_{\alpha=1}<0$ and using $S^{*}(\alpha=1)=R \frac{\psi R}{r}(1+$ $\left.E_{0}\right)-\kappa D_{u}$ yields: 


$$
\frac{F\left[R\left(1+E_{0}\right) \frac{\psi R}{r}-\kappa D_{u}\right]}{f\left[R\left(1+E_{0}\right) \frac{\psi R}{r}-\kappa D_{u}\right]}<\frac{\left(1-\frac{\psi R}{r}\right)}{\psi\left(\frac{R}{r}-1\right)}\left[(\kappa-1) D_{u}+(1-\psi) R\left(1+E_{0}\right)\right]
$$

The argument of the left-hand side increases in $R$, while the right-hand side decreases in $R$. Thus, $\alpha^{*}<1$ for any $R<\bar{R}$ implicitly defined by

$$
\frac{F\left[\bar{R}\left(1+E_{0}\right) \frac{\psi \bar{R}}{r}-\kappa D_{u}\right]}{f\left[\bar{R}\left(1+E_{0}\right) \frac{\psi \bar{R}}{r}-\kappa D_{u}\right]} \equiv \frac{\left(1-\frac{\psi \bar{R}}{r}\right)}{\psi\left(\frac{\bar{R}}{r}-1\right)}\left[(\kappa-1) D_{u}+(1-\psi) \bar{R}\left(1+E_{0}\right)\right]
$$

Since the right-hand side of this expression again goes to positive infinity for $R \rightarrow \frac{r}{\psi}$, and since the left-hand side remains positive but finite, an upper bound $\bar{R}<\frac{r}{\psi}$ exists.

Next, we show that $\bar{R}>\underline{R}$ for any given $D_{u}$. Since the bankruptcy threshold $S^{*}$ decreases in asset encumbrance $\alpha$ (Lemma 2), the left-hand side in condition (31) is smaller than the left-hand side in condition (30). Moreover, the right-hand side in condition (31) is larger than the right-hand side in condition (30) because of the additional term. As a result, $\bar{R}>\underline{R}$, which justifies our labels. In sum, $\alpha^{*} \in(0,1)$ for any $R \in(\underline{R}, \bar{R})$.

\section{Proof of Proposition 3 and Corollary 2}

We compute comparative statics of $\alpha^{*}$ with respect to $y \in\left\{R, \gamma, \psi, r, E_{0}, D_{u}\right\}$ and the distribution of the balance sheet shock. We focus on intermediate investment profitability, $R \in(\underline{R}, \bar{R})$, in order to guarantee an interior solution $\alpha^{*} \in(0,1)$. The implicit function

theorem yields $\frac{d \alpha^{*}}{d y}=-\frac{\pi_{\alpha y}}{\pi_{\alpha \alpha}}$. To derive the partial derivatives, we use the bankruptcy threshold in equation (26) together with the derivative of the expected profit with respect to asset encumbrance, $\pi_{\alpha}$, in equation $(27)$.

First, we report the partial derivatives of the threshold $S^{* *} \equiv S^{*}\left(\alpha^{*}\right)$, where the relative return is $z=\frac{R}{r}$ : 


$$
\begin{aligned}
\frac{\partial S^{* *}}{\partial \alpha} & =-R\left(1+E_{0}\right)(1-\psi z)<0, \\
\frac{\partial S^{* *}}{\partial D_{u}} & =-\kappa<0, \\
\frac{\partial S^{* *}}{\partial R} & =\left(1+E_{0}\right)\left[1-\alpha^{*}(1-2 \psi z)\right]>0, \\
\frac{\partial S^{* *}}{\partial \gamma} & =-\left(\frac{1}{\psi}-1\right) D_{u}<0, \\
\frac{\partial S^{* *}}{\partial r} & =-\alpha^{*} \psi z^{2}\left(1+E_{0}\right)<0, \\
\frac{\partial S^{* *}}{\partial E_{0}} & =R\left[1-\alpha^{*}(1-\psi z)\right]>0, \\
\frac{\partial S^{* *}}{\partial \psi} & =R z \alpha^{*}+\frac{\gamma D_{u}}{\psi^{2}}>0 .
\end{aligned}
$$

Second, we report the partial derivatives of the implicit function defined by $\pi_{\alpha}\left(\alpha^{*}\right)=0$ :

$$
\begin{aligned}
\pi_{\alpha \alpha}= & \left(\psi(z-1) f\left(S^{* *}\right)-(1-\psi z) E\left(S^{* *}\right) f^{\prime}\left(S^{* *}\right)\right) \frac{\partial S^{* *}}{\partial \alpha} \\
& -(1-\psi z) f\left(S^{* *}\right)(1-\psi) R\left(1+E_{0}\right)<0 \\
\pi_{\alpha D_{u}=}= & f\left(S^{* *}\right)[\psi z+(1-\psi) \kappa-1]+\kappa(1-\psi z) f^{\prime}\left(S^{* *}\right) E\left(S^{* *}\right)<0 \\
\pi_{\alpha \gamma}= & {\left[(1-\psi) f\left(S^{* *}\right)-(1-\psi z) f^{\prime}\left(S^{* *}\right) E\left(S^{* *}\right)\right] \frac{\partial S^{* *}}{\partial \gamma}<0 } \\
\pi_{\alpha r}= & -\psi \frac{R}{r^{2}}\left[F\left(S^{* *}\right)+f^{\prime}\left(S^{* *}\right) E\left(S^{* *}\right)\right]+\psi(z-1) f\left(S^{* *}\right) \frac{\partial S^{* *}}{\partial r} \\
& -(1-\psi z) f^{\prime}\left(S^{* *}\right) E\left(S^{* *}\right) \frac{\partial S^{* *}}{\partial r}<0 \\
& (z-1) F\left(S^{* *}\right)+\psi(z-1) f\left(S^{* *}\right) \frac{\partial S^{* *}}{\partial \psi}+z f\left(S^{* *}\right) E\left(S^{* *}\right) \\
\pi_{\alpha \psi}= & (1-\psi z) f^{\prime}\left(S^{* *}\right) \frac{\partial S^{* *}}{\partial \psi} E\left(S^{* *}\right)+(1-\psi z) f\left(S^{* *}\right)\left[\alpha^{*} R\left(1+E_{0}\right)+\frac{\gamma D_{u}}{\psi^{2}}\right]>0 .
\end{aligned}
$$

Third, by the implicit function theorem, we obtain the first four comparative statics reported in Proposition 3: $\frac{d \alpha^{*}}{d \psi}>0, \frac{d \alpha^{*}}{d \gamma}<0, \frac{d \alpha^{*}}{d r}<0$, and $\frac{d \alpha^{*}}{d D_{u}}<0$.

Fourth, suppose that the balance sheet shock distribution $\widetilde{F}$ stochastically dominates the distribution $F$ according to the reverse hazard rate. This implies that 


$$
\frac{\widetilde{f}}{\widetilde{F}} \geq \frac{f}{F},
$$

or, equivalently, $F / f \geq \widetilde{F} / \widetilde{f}$. Let $\widetilde{\pi}_{\alpha}\left(\widetilde{\alpha}^{*}\right)=0$ denote the implicit function defining the privately optimal level of asset encumbrance, $\widetilde{\alpha}^{*}$, under the balance sheet shock distribution $\widetilde{F}$. Therefore, we have that $\tilde{\pi}_{\alpha} \leq \pi_{\alpha}$ for all levels of encumbrance. Since $\tilde{\pi}_{\alpha \alpha}<0$ and $\pi_{\alpha \alpha}<0$, it follows that the privately optimal levels of encumbrance satisfy $\widetilde{\alpha}^{*} \geq \alpha^{*}$.

Finally, we consider the comparative statics of the privately optimal level of asset encumbrance with respect to initial bank capital and investment profitability:

$$
\begin{aligned}
\pi_{\alpha E_{0}}= & {\left[\psi(z-1) \frac{\partial S^{* *}}{\partial E_{0}}-(1-\psi z) \alpha^{*} R(1-\psi)\right] f\left(S^{* *}\right)-(1-\psi z) f^{\prime}\left(S^{* *}\right) E\left(S^{* *}\right) } \\
\pi_{\alpha R}= & \frac{\psi}{r} F\left(S^{* *}\right)-(1-\psi z) E\left(S^{* *}\right) f^{\prime}\left(S^{* *}\right) \\
& +f\left(S^{* *}\right)\left[\psi(z-1) \frac{\partial S^{* *}}{\partial R}+\frac{\psi}{r} E\left(S^{* *}\right)-(1-\psi z) \alpha^{*}(1-\psi)\left(1+E_{0}\right)\right]
\end{aligned}
$$

Since $f^{\prime}\left(S^{* *}\right) \leq 0$, a sufficient condition for $\pi_{\alpha E_{0}}>0$ is $g(z) \equiv z^{2}+\frac{1-2 \psi}{\psi} z-\frac{1-\psi}{\psi^{2}}>0$. Let the two roots be $z_{1}<z_{2}$ such that $g(z)>0$ for $z<z_{1}$ and $z>z_{2}$. One can show that $z_{1}<1$, which is not a valid solution. However, one can show that $z_{2}<\frac{1}{\psi}$, the upper bound on $z$, where

$$
z_{2} \equiv \frac{2 \psi-1+\sqrt{4(1-\psi)^{2}+1}}{2 \psi}
$$

Thus, $z \in\left(z_{2}, \frac{1}{\psi}\right)$ suffices for $\pi_{\alpha E_{0}}>0$. Let $\bar{r} \equiv \frac{R}{z_{2}}$, such that $g(z)>0 \forall r<\bar{r}$, so $\pi_{\alpha E_{0}}>0$ and $\frac{d \alpha^{*}}{d E_{0}}>0$ by the implicit function theorem. One can also show that $g(z)>0$ is sufficient for $\pi_{\alpha R}>0$, which yields $\frac{d \alpha^{*}}{d R}>0$.

Consider the special case of a uniform distribution, $S \sim \mathcal{U}\left[0, R\left(\omega+1+E_{0}\right)\right]$, where the upper bound is designed to always exceed $S_{\max }$. The first-order condition of the privately optimal level of asset encumbrance is linear. Rewriting yields the expression stated in Corollary 2, and differentiation with respect to $E_{0}$ yields 


$$
\frac{d \alpha^{*}}{d E_{0}}=\frac{[\psi z+(1-\psi) \kappa-1] D_{u}}{R\left(1+E_{0}\right)^{2}\left[1-2 \psi-\psi^{2} z(z-2)\right]}>0
$$

since the numerator is unambiguously positive and the denominator is positive between the

two roots, $\frac{2 \psi-1}{\psi}<z<\frac{1}{\psi}$, which includes the full support of the relative return. Similarly,

$$
\frac{d \alpha^{*}}{d R}=\frac{[\psi z+(1-\psi) \kappa-1] D_{u}}{R^{2}\left(1+E_{0}\right)\left[1-2 \psi-\psi^{2} z(z-2)\right]}>0
$$

which is unambiguously positive for the same reason.

\section{E Proof of Proposition 4}

The equilibrium face value of unsecured debt $D_{u}^{*}$ is implicitly defined by the binding participation constraint of risk-neutral investors, $V\left(D_{u}^{*}\right)=r$. The proof of existence and uniqueness of $D_{u}^{*}$ is in four steps. First, for any given $D_{u}$, the value of the unsecured debt claim decreases in the level of asset encumbrance:

$$
\frac{\partial V}{\partial \alpha^{*}}=D_{u}[1-\kappa \psi] f\left(S^{* *}\right) \frac{d S^{* *}}{d \alpha^{*}}-\psi R\left(1+E_{0}\right)(1-\psi z) \int_{S^{* *}}^{S_{\max }^{*}} d F(S)<0
$$

Intuitively, greater asset encumbrance reduces both the pool of unencumbered assets and the range of balance sheet shocks for which unsecured debt holders are repaid in full, so the overall effect on the value of the unsecured debt claim is negative.

Second, risk-neutral investors never accept a debt claim with face value $D_{u}=r$ :

$$
\begin{aligned}
V\left(D_{u}=r\right) & =r F\left(S^{* *}\right)+\psi \int_{S^{* *}}^{S_{\max }^{*}}\left(S_{\max }^{*}-S\right) d F(S) \\
& <r\left(F\left(S^{* *}\right)+\psi \kappa\left[F\left(S_{\max }^{*}\right)-F\left(S^{* *}\right)\right]\right)<r .
\end{aligned}
$$

Third, the value of the unsecured debt claim changes with its face value according to $\frac{d V}{d D_{u}}=$ $\frac{\partial V}{\partial \alpha^{*}} \frac{\partial \alpha^{*}}{\partial D_{u}}+\frac{\partial V}{\partial D_{u}}$, where $\frac{\partial S^{* *}}{\partial D_{u}}=-\kappa$ and 


$$
\begin{aligned}
\frac{\partial V}{\partial D_{u}} & =F\left(S^{* *}\right)-\kappa(1-\psi \kappa) D_{u} f\left(S^{* *}\right) \\
& =f\left(S^{* *}\right) \frac{1-\psi z}{\psi(z-1)}\left[(\kappa-1) D_{u}+\alpha^{*}(1-\psi) R\right]-\kappa(1-\psi \kappa) D_{u} f\left(S^{* *}\right),
\end{aligned}
$$

where we used the first-order condition for $\alpha^{*}$. Since the indirect effect via $\alpha^{*}$ is positive, $\frac{\partial V}{\partial \alpha^{*}} \frac{\partial \alpha^{*}}{\partial D_{u}}>0$, and since $\alpha^{*}(1-\psi) R f\left(S^{* *}\right) \geq 0$, a sufficient condition for $\frac{d V}{d D_{u}}>0$ is that the term multiplying $f\left(S^{* *}\right) D_{u}$ is non-negative, $-\kappa(1-\psi \kappa)+\frac{1-\psi z}{\psi(z-1)}(\kappa-1) \geq 0$. Rewriting yields an upper bound on investment profitability relative to the return on storage:

$$
z \leq \bar{z} \equiv \frac{\kappa-1+\kappa \psi(1-\kappa \psi)}{\psi(\kappa-1)+\kappa \psi(1-\kappa \psi)} \in\left(1, \frac{1}{\psi}\right)
$$

which can be written as $R \leq \tilde{R}$. This condition ensures the monotonicity of the unsecured debt claim in its face value, $\frac{d V}{d D_{u}}>0$, and suffices for the uniqueness of $D_{u}^{*}$ (if it exists).

Fourth, existence requires that risk-neutral investors accept the debt claim for a feasible face value. Since the banker can promise at most $D_{u}=R$, we require $V\left(D_{u}=R\right)>r$ because of monotonicity. Since $S^{* *}(R)=R\left[\left(1+E_{0}\right)\left(1-\alpha^{*}(1-\psi z)\right)-\kappa\right]$ :

$$
r<R F\left(S^{* *}(R)\right)+\psi \int_{S^{* *}(R)}^{S_{\max }^{*}}\left(S_{\max }^{*}-S\right) d F(S)
$$

Since greater asset encumbrance dilutes the unsecured debt claim, as shown in the first point, a sufficient condition in terms of exogenous parameters of the model can be obtained by evaluating this inequality at $\alpha^{*}=1$ :

$$
r \leq R F\left(R\left[\left(1+E_{0}\right) \psi z-\kappa\right]\right)+\psi \int_{R\left[\left(1+E_{0}\right) \psi z-\kappa\right]}^{R \psi z\left(1+E_{0}\right)}\left(R\left[\left(1+E_{0}\right) \psi z-\kappa\right]-S\right) d F(S) .
$$

This condition suffices for the existence of $D_{u}^{*}$. Figure 5 illustrates. 


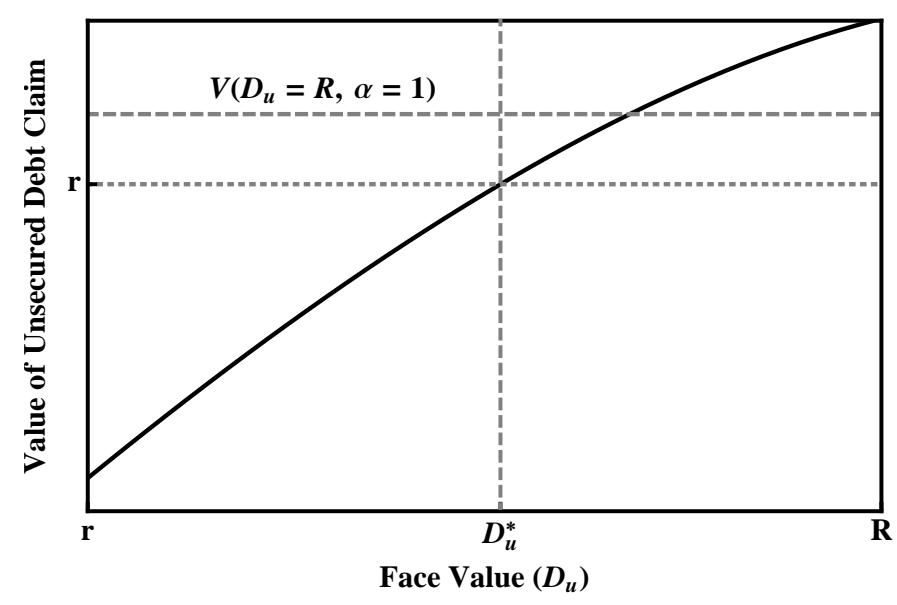

Figure 5: Unsecured debt claim: its value increases in the face value.

\section{F Proof of Proposition 5}

The bound $\breve{S}=R\left(1+E_{0}+\omega\right)-\kappa r$ is constructed to always ensure that $\breve{S}>S^{*}$ (because $\alpha^{*} \geq 0$ and $D_{u}^{*}>r$ ). By Proposition 2, which defines the privately optimal level of asset encumbrance, $\alpha^{*}=\hat{\alpha}^{*}$ because both $F$ and $\hat{F}$ are identical for any $S<\breve{S}$. Thus, the difference in distribution affects the value of the unsecured debt claim only via the liquidation value in bankruptcy, but not via changes in asset encumbrance. Next, observe that $V\left(D_{u} \mid \hat{F}\right)>V\left(D_{u} \mid F\right)$, for any given $D_{u}$, because of the lower tail risk under $\hat{F}$. Since risk-neutral investors always receive their outside option in expectation, we have $V\left(\hat{D}_{u}^{*} \mid \hat{F}\right)=r=V\left(D_{u}^{*} \mid F\right)$. Since $\frac{d V}{d D_{u}}>0$ as showed before, it follows that $\hat{D}_{u}^{*}<D_{u}^{*}$.

\section{G Proof of Proposition 6}

The first-order condition is a straightforward extension of the model without public guarantees and follows directly from the problem in (10). The comparative static $\frac{d \alpha_{m}^{*}}{d m}>0$ follows from the implicit function theorem, since $\frac{d \alpha_{m}^{*}}{d m}=-\frac{\pi_{\alpha m}}{\pi_{\alpha \alpha}}>0$. The sign arises from $f^{\prime} \leq 0, S_{m}^{* *} \equiv S_{m}^{*}\left(\alpha_{m}^{*}\right), \frac{\partial S_{m}^{*}}{\partial \alpha}=-R\left(1+E_{0}\right)(1-\psi z)<0, \frac{\partial S_{m}^{*}}{\partial m}=\kappa D_{u}-D_{g}>0$, $E\left(S_{m}^{* *}\right)=(\kappa-1)(1-m) D_{u}+\alpha_{m}^{*}(1-\psi) R\left(1+E_{0}\right)>0$, as well as 


$$
\begin{aligned}
\pi_{\alpha \alpha} & \equiv R^{2}\left(1+E_{0}\right)^{2}(1-\psi z)\left[E\left(S_{m}^{* *}\right)(1-\psi z) f^{\prime}\left(S_{m}^{* *}\right)-\{\psi(z-1)+1-\psi\} f\left(S_{m}^{* *}\right)\right]<0 \\
\pi_{\alpha m} & \equiv R\left(1+E_{0}\right)\left[f\left(S_{m}^{* *}\right) \psi(z-1)\left(\kappa D_{u}-D_{g}\right)-(1-\psi z)\left\{f^{\prime}\left(S_{m}^{* *}\right) E\left(S_{m}^{* *}\right)\left[\kappa D_{u}-D_{g}\right]\right.\right. \\
& \left.\left.-f\left(S_{m}^{* *}\right)(\kappa-1) D_{u}\right\}\right]>0 .
\end{aligned}
$$

\section{H Proof of Lemma 3}

The partial derivatives of the expected cost to the guarantor with respect to the level of asset encumbrance and the coverage of the guarantee are:

$$
\begin{aligned}
\frac{\partial C}{\partial \alpha} & \equiv C_{\alpha}=\psi(1-\psi z) R\left(1+E_{0}\right)\left[F\left(S_{\max }\right)-F\left(S_{\max }-\frac{m D_{g}}{\psi}\right)\right]>0 \\
\frac{\partial^{2} C}{\partial \alpha^{2}} & \equiv C_{\alpha \alpha}=-\psi(1-\psi z)^{2} R^{2}\left(1+E_{0}\right)^{2}\left[f\left(S_{\max }\right)-f\left(S_{\max }-\frac{m D_{g}}{\psi}\right)\right] \geq 0 \\
\frac{\partial C}{\partial m} & \equiv C_{m}=D_{g}\left[1-F\left(S_{\max }-\frac{m D_{g}}{\psi}\right)\right]>0 \\
\frac{\partial^{2} C}{\partial \alpha \partial m} & \equiv C_{\alpha m}=(1-\psi z) R\left(1+E_{0}\right) D_{g} f\left(S_{\max }-\frac{m D_{g}}{\psi}\right)>0
\end{aligned}
$$

\section{I $\quad$ Proof of Proposition 7}

As for preliminaries, we have $W_{\alpha \alpha} \equiv \pi_{\alpha \alpha}-(1+\xi) C_{\alpha \alpha}<0$ and $[0,1]$ is a closed set, so there exists a unique global welfare maximum at the constrained efficient level of encumbrance, $\alpha_{P}$. If interior, this level solves the first-order condition $\pi_{\alpha}\left(\alpha_{P}\right)=(1+\xi) C_{\alpha}\left(\alpha_{P}\right)$. The associated level of fragility is $S_{P} \equiv S_{m}^{*}\left(\alpha_{P}\right)$.

To establish constrained inefficiency of the privately optimal level of asset encumbrance, note that $W_{\alpha}\left(\alpha_{m}^{*} ; m\right)=-C_{\alpha}\left(\alpha_{m}^{*} ; m\right)<0$. Since $\alpha_{P}$ solves $W_{\alpha}\left(\alpha_{P} ; m\right)=0$, and the objective function of the planner is globally concave, $W_{\alpha \alpha}<0$, it follows that $\alpha_{P}<\alpha_{m}^{*}$. 
We turn to the comparative statics of the gap between the privately optimal and constrained efficient encumbrance levels. Since $W_{\alpha \xi}=-C_{\alpha}<0, \frac{d \alpha_{P}}{d \xi}=-\frac{W_{\alpha \xi}}{W_{\alpha \alpha}}<0$ by the implicit function theorem (IFT), which yields the second comparative static, $\frac{d\left(\alpha_{m}^{*}-\alpha_{P}\right)}{d \xi}>0$ $\left(\alpha_{m}^{*}\right.$ is independent of $\xi$ ). Similarly, the first comparative static obtains if $\frac{d \alpha_{P}}{d m}<\frac{d \alpha_{m}^{*}}{d m}$. Let $W_{\alpha m} \equiv \pi_{\alpha m}-C_{\alpha m}$. By the IFT for both $\alpha_{P}$ and $\alpha_{m}^{*}$, this inequality requires $-\frac{W_{\alpha m}}{W_{\alpha \alpha}}<$ $-\frac{\pi_{\alpha m}}{\pi_{\alpha \alpha}} \Leftrightarrow-\frac{\pi_{\alpha m}-(1+\xi) C_{\alpha m}}{\pi_{\alpha \alpha}-(1+\xi) C_{\alpha \alpha}}<-\frac{\pi_{\alpha m}}{\pi_{\alpha \alpha}} \Leftrightarrow C_{\alpha m} \pi_{\alpha \alpha}<\pi_{\alpha m} C_{\alpha \alpha}$, which always holds.

Turning to bank fragility, excessive fragility and the comparative statics of the bankruptcy threshold with respect to guarantee coverage arise from $\alpha_{m}^{*}>\alpha_{P}, \frac{d\left(\alpha_{m}^{*}-\alpha_{P}\right)}{d m}>0$, and $\frac{d S_{m}^{*}}{d \alpha}<0$. Similarly, the comparative statics on the dead-weight loss follows from $\frac{d \alpha_{P}}{d \xi}<0$ and $\frac{d \alpha_{m}^{*}}{d \xi}=0$.

\section{J Proof of Propositions $8-10$}

We consider the cap on asset encumbrance and Proposition 8 first. From Proposition 7, we know that the bank's unconstrained choice of asset encumbrance, $\alpha_{m}^{*}$, is greater than the constrained efficient level, $\alpha_{P}$. Moreover, because of the global concavity of $\pi$, we have $\pi_{\alpha}>0$ for any $\alpha<\alpha_{m}^{*}$. Therefore, introducing the constraint $\alpha \leq \alpha_{P}$ into the bank's program at the secured funding round at $t=0$ implies that the constraint will always bind, $\alpha_{m}^{* *}=\alpha_{P}$.

Second, we consider a minimum capital requirement and Proposition 9. The minimum capital ratio, $e(\alpha) \geq \underline{e} \equiv \frac{E_{0}}{\left(1+E_{0}\right)\left(1+\psi z \alpha_{P}\right)}$, can be rewritten as a cap on the level of asset encumbrance, $\alpha \leq \alpha_{P}$. As before, introducing a minimum capital ratio as an additional constraint in the bank's program at the secured funding round yields constrained efficiency.

Third, we consider the encumbrance surcharge and Proposition 10. We show by contradiction that there exists no continuous schedule of asset encumbrance surcharge. Suppose

such a schedule exists and call it $\tilde{\Delta}$. To ensure that the constrained privately optimal level of asset encumbrance does not exceed $\alpha_{P}$, it must be true that $\tilde{\Delta}(\alpha)>0$ for any $\alpha>\alpha_{P}$. 
(Intuitively, the surcharge is high enough to prevent the banker from increasing the asset encumbrance level beyond $\alpha_{P}$, as is optimal without constraint; see Propositions 6 and 7.) By continuity, $\tilde{\Delta}\left(\alpha_{P}\right)>0$. Using the expression for the bankruptcy threshold in (16), we obtain $S_{m}^{\Delta}\left(\alpha_{P}\right)<S_{P}$, contradicting the supposed constrained efficiency of the schedule $\tilde{\Delta}$.

Finally, we show by example that there exists a schedule that is sufficiently discontinuous at $\alpha_{P}$ and attains constraint efficiency. Consider the example in the main text, $\hat{\Delta}$. The surcharge wipes out all unencumbered assets if $\alpha>\alpha_{P}$ is chosen, but does not affect the problem if $\alpha \leq \alpha_{P}$. Therefore, we can effectively write the discontinuous schedule of asset encumbrance surcharges as a constraint $\alpha \leq \alpha_{P}$ on the banker's problem. We have already shown that this constraint attains constrained efficiency, which concludes the proof. 